\title{
Magnetic Resonance Imaging in Tauopathy Animal Models
}

\author{
Ruiqing $\mathrm{Ni}^{1,2 *}$ \\ ${ }^{1}$ Institute for Biomedical Engineering, ETH Zurich and University of Zurich, Zurich, Switzerland, ${ }^{2}$ Institute for Regenerative \\ Medicine, University of Zurich, Zurich, Switzerland
}

\section{OPEN ACCESS}

Edited by:

Rachel Bennett,

Massachusetts General Hospital and Harvard Medical School,

United States

Reviewed by:

Zhiliang Wei,

Johns Hopkins University,

United States

lan Francis Harrison,

University College London,

United Kingdom

*Correspondence:

Ruiqing $\mathrm{Ni}$

ni@biomed.ee.ethz.ch

Specialty section:

This article was submitted to

Alzheimer's Disease and Related

Dementias,

a section of the journal

Frontiers in Aging Neuroscience

Received: 08 October 2021 Accepted: 27 December 2021

Published: 25 January 2022

Citation:

Ni R (2022) Magnetic Resonance

Imaging in Tauopathy Animal Models.

Front. Aging Neurosci. 13:791679.

doi: 10.3389/fnagi.2021.791679
The microtubule-associated protein tau plays an important role in tauopathic diseases such as Alzheimer's disease and primary tauopathies such as progressive supranuclear palsy and corticobasal degeneration. Tauopathy animal models, such as transgenic, knock-in mouse and rat models, recapitulating tauopathy have facilitated the understanding of disease mechanisms. Aberrant accumulation of hyperphosphorylated tau contributes to synaptic deficits, neuroinflammation, and neurodegeneration, leading to cognitive impairment in animal models. Recent advances in molecular imaging using positron emission tomography (PET) and magnetic resonance imaging (MRI) have provided valuable insights into the time course of disease pathophysiology in tauopathy animal models. High-field MRI has been applied for in vivo imaging in animal models of tauopathy, including diffusion tensor imaging for white matter integrity, arterial spin labeling for cerebral blood flow, resting-state functional MRI for functional connectivity, volumetric MRI for neurodegeneration, and MR spectroscopy. In addition, MR contrast agents for non-invasive imaging of tau have been developed recently. Many preclinical $\mathrm{MRI}$ indicators offer excellent translational value and provide a blueprint for clinical MRI in the brains of patients with tauopathies. In this review, we summarized the recent advances in using MRI to visualize the pathophysiology of tauopathy in small animals. We discussed the outstanding challenges in brain imaging using MRI in small animals and propose a future outlook for visualizing tau-related alterations in the brains of animal models.

Keywords: magnetic resonance imaging (MRI), tau, animal model, FTD (frontotemporal dementia), Alzheimer's disease, neurodegenaration

\section{INTRODUCTION}

Six microtubule-associated protein tau (MAPT) isoforms are expressed in the adult human brain and are further categorized into 4-repeat (4R) and 3-repeat (3R) species (Lee et al., 2001). Tauopathy diseases include Alzheimer's disease (AD) and primary tauopathies such as progressive supranuclear palsy (PSP), corticobasal degeneration (CBD), and frontotemporal dementia (FTD) with Parkinsonism linked to chromosome 17, and Pick's disease (Ballatore et al., 2007). Primary tauopathies are pathologically characterized by the aggregation of hyperphosphorylated tau protein into neurofibrillary tangles, neuropil threads, and argentophilic glial inclusions (Lee et al., 2001). Thus, tau has been an important target in therapeutic development for $\mathrm{AD}$ and primary tauopathies, with several immunotherapies, antisense oligonucleotides, and aggregation inhibitors under clinical trials (DeVos et al., 2017; Congdon and Sigurdsson, 2018; 
Boxer et al., 2019, 2020; Ayalon et al., 2021; Grossman, 2021; Mullard, 2021; Novak et al., 2021). Animal models recapitulating tauopathy have facilitated the understanding of disease mechanisms and the development of treatment strategies (Albert et al., 2019; Roberts et al., 2020; Ayalon et al., 2021), including transgenic mouse lines P301S (PS19), EC-tau, P301L (JNPL3, rTg4510, pR5), rTg21221 (Lewis et al., 2000; Ramsden et al., 2005; Santacruz et al., 2005; Yoshiyama et al., 2007; Hoover et al., 2010; de Calignon et al., 2012) and rat models (Filipcik et al., 2012). In addition, knock-out hTau (Andorfer et al., 2003) and knock-in mouse models (Hashimoto et al., 2019; Saito et al., 2019; Hosokawa et al., 2021) have been recently developed. Animal models exhibit tau accumulation, neuroinflammation, synaptic dysfunction, brain regional atrophy, and cognitive impairment to different extents (Götz et al., 2018; Ishikawa et al., 2018; Ising et al., 2019). Magnetic resonance imaging (MRI) has been widely used to non-invasively probe the tissue changes associated with cerebral tau pathology in patients with $\mathrm{AD}$ and FTD (Du et al., 2006; Boxer et al., 2020; Young et al., 2021). Regional atrophy assessed by $\mathrm{T}_{2}$-weighted MRI, white matter integrity assessed by diffusion tensor imaging (DTI), and cerebral perfusion measured by arterial spin labeling (ASL) have emerged as potential biomarkers in AD and FTD. Recent advances in MRI and contrast agents (Wahsner et al., 2019) have provided valuable insights into the time course of disease pathophysiology in tau animal models, including tau, neuroinflammation, and structural and functional alterations.

\section{TAU IMAGING}

Tau is located intracellularly and is subject to posttranslational modifications, including phosphorylation, acetylation, ubiquitylation, and truncation. Tau aggregates into nanofibrils with cofactors (Goedert et al., 1996) and displays typical sigmoidal kinetics of nucleation-dependent protein aggregation (Chakraborty et al., 2021). The smaller aggregates, tau oligomers, are considered more neurotoxic than the neurofibrillary tangle, induce synaptic and mitochondrial dysfunction, and impair memory functions in animal models (Lasagna-Reeves et al., 2011). Tau imaging has been even more challenging than amyloid imaging due to the intracellular location and size of tau aggregates, as well as the different tau isoforms (Villemagne et al., 2015). Positron emission tomography (PET) imaging of tau in tauopathy mouse models using various tau-targeted radioligands has been established (Maruyama et al., 2013; Brendel et al., 2016; Ono et al., 2017; Ishikawa et al., 2018; Ni et al., 2018; Tagai et al., 2020; Chaney et al., 2021; Cao et al., 2022). In addition, fluorescence imaging, two-photon microscopy, and photoacoustic imaging methods have been developed for in vivo mapping of tau accumulation in animal models (Wu et al., 2018; Calvo-Rodriguez et al., 2019; Ni et al., 2020a; Vagenknecht et al., 2021). To date, a few MRI tau imaging studies have been reported assisted with contrast agents (Table 1). Two MRI contrast agents have been reported for detecting tau in animal models in vivo. Yanagisawa et al. (2018) reported that the $\left[{ }^{19} \mathrm{~F}\right]$ buta-1,3-diene derivative Shiga-X35 allowed the detection of tau aggregates in the forebrain region of 8-9-month-old female rTg4510 mice compared with wild-type mice at $7 \mathrm{~T}$ MRI. The detection was verified by colocalization with anti-phosphorylated tau antibody AT8-positive tau deposits. Badachhape et al. (2020) and Parekh et al. (2021) demonstrated tau imaging using the DNA aptamertargeted liposomal-Gd nanoparticle TauX, which binds to the surface of hyperphosphorylative cells, for $\mathrm{T}_{1}$-weighted spin echo MRI in PS19 mice (Figure 1A). Increased TauX-enhanced post-contrast MR signal enhancement was detected at 2 months of age in PS19 mice (which showed tauopathy 4-6 months later) compared with wild-type mice, with an accuracy of approximately 0.8 (Figure 1B).

\section{FUNCTIONAL IMAGING}

Hyperneuronal activity has been shown to enhance tau secretion and exacerbate tau pathology in several tauopathy mouse models, including rTg4510, EC-Tau (Wu et al., 2016), Thy-Tau22 (Gomez-Murcia et al., 2020), and the TAU58/2 lines (Przybyla et al., 2020). Pathological tau accumulates mainly in excitatory neurons rather than in inhibitory neurons, leading to neuronal network dysfunction and neural circuit impairment (Busche et al., 2008; Fu et al., 2019). Functional imaging techniques, such as manganese-enhanced MRI (MEMRI), ASL, restingstate functional MRI (rs-fMRI), and contrast-enhanced fMRI, have been widely used to probe brain functional alterations in small animals.

\section{Resting-State Functional MRI and Task-Based fMRI}

Blood-oxygen-level-dependent (BOLD) signals measured by rsfMRI are widely used for non-invasive mapping of brain function between neural activity and its accompanying hemodynamics. Recent studies have shown that the spreading of misfolded tau follows a disease-specific region-dependent pattern in the brain not only in the anatomically connected regions but also in the functionally connected regions in patients with AD (Franzmeier et al., 2020; Vogel et al., 2021) and with FTD (Kim et al., 2020; Spinelli et al., 2021; Young et al., 2021). The default mode network (DMN) is a set of network nodes consisting of the medial prefrontal cortex, the posterior cingulate/precuneus, inferior parietal lobe, lateral temporal cortex, and hippocampal formation (Buckner and DiNicola, 2019). In patients with primary tauopathy, DMN regions are affected at an early stage (Zhou et al., 2010; Lee et al., 2014). Few fMRI studies have been reported thus far in tau mouse models (Table 1). As these studies are performed in different mouse lines, a direct comparison of the results is infeasible. Green et al. (2019) showed that functional networks were impaired by elevated tau accumulation in TauRD/ $\Delta \mathrm{K} 280$ mice compared with wildtype mice and were reversible by doxycycline treatment to regulate soluble tau for 8 weeks (under $1.5 \%$ isoflurane during rs-fMRI) (Figure 1C). Degiorgis et al. (2020) demonstrated that there was hyperactivated functional connectivity in the hippocampus, amygdala, and isocortical areas in Thy-Tau 22 mice at an early stage ( 5 months of age) compared with wild-type mice 
TABLE 1 | Summary of MRI in animal models of tauopathy.

\begin{tabular}{|c|c|c|c|}
\hline Target & MRI sequence & Animal model & References \\
\hline \multirow[t]{6}{*}{ WM } & DTI & pR5 mice & Massalimova et al., 2021; Soni et al., 2021 \\
\hline & & rTg4510 mice & Sahara et al., 2014; Wells et al., 2015b; Colgan et al., 2016; Holmes et al., 2016 \\
\hline & & TauRD/ $\mathrm{K} 280$ mice & Green et al., 2019 \\
\hline & & Thy-Tau22 & Degiorgis et al., 2020 \\
\hline & & JNPL3 mice & Nishioka et al., 2019 \\
\hline & & Tg601 mice & Hara et al., 2017 \\
\hline \multirow[t]{2}{*}{ Tau } & ${ }^{19}$ F Shiga-X35 & rTg4510 mice & Yanagisawa et al., 2018 \\
\hline & TauX, $T_{1} w-S E$ & PS19 mice & Badachhape et al., 2020; Parekh et al., 2021 \\
\hline \multirow[t]{7}{*}{ Atrophy } & $\mathrm{T}_{2}$ & rTg4510 mice & $\begin{array}{l}\text { Xie et al., 2010; Yang et al., 2011; Wells et al., 2015b; Holmes et al., 2016; Ishikawa } \\
\text { et al., 2018; Ni et al., 2018; Ma et al., 2019; Barron et al., 2020; Park et al., 2020; } \\
\text { Wang et al., } 2020\end{array}$ \\
\hline & & hTau mice & Hashimoto et al., 2019 \\
\hline & & EC-tau mice & Fung et al., 2020 \\
\hline & & pR5 mice & Kindler et al., 2021 \\
\hline & & rTg21221 mice & Musi et al., 2018 \\
\hline & & PS19 mice & Wu et al., 2019; Takeuchi et al., 2020; Lee et al., 2021 \\
\hline & & R962-hTau rats & Malcolm et al., 2019 \\
\hline \multirow[t]{2}{*}{ Texture } & $T_{2}^{*} W$ MRTA, $T_{2}^{*} W$ & rTg4510 mice & Colgan et al., 2017; O'Callaghan et al., 2017 \\
\hline & QSM & & O'Callaghan et al., 2017 \\
\hline \multirow[t]{7}{*}{ Neurochemical profiles } & ${ }^{1} \mathrm{HMRS}$ & rTg4510 mice & Yang et al., 2011; Kim et al., 2017 \\
\hline & ${ }^{1} \mathrm{H},{ }^{13} \mathrm{C} \mathrm{MRS}$ & pR5 mice & Nilsen et al., 2013 \\
\hline & CEST & Tau4R $\Delta \mathrm{K}(\mathrm{Tau})$ mice & Chen et al., 2021 \\
\hline & & rTg4510 mice & Wells et al., 2015b; Holmes et al., 2016 \\
\hline & & Tau4R $\Delta \mathrm{K}(\mathrm{Tau})$ mice & Chen et al., 2020 \\
\hline & & hTau mice & Lauretti et al., 2017 \\
\hline & & PS19 mice & Crescenzi et al., 2014, 2017 \\
\hline Optic nerve & $\mathrm{T}_{2}$ & rTg4510 mice & Harrison et al., 2019 \\
\hline $\mathrm{Fe}, \mathrm{Ca}$ & SWI & pR5 mice & Ni et al., 2020b \\
\hline CVR & ASL & rTg4510 mice & Wells et al., $2015 a$ \\
\hline $\mathrm{CMRO}_{2}$ & TRUST. PC & Tau4R $\Delta \mathrm{K}$ (Tau) mice & Wei et al., 2021 \\
\hline \multirow[t]{5}{*}{$\mathrm{CBF}$} & ASL & rTg4510 mice & Wells et al., 2015b; Holmes et al., 2016; Park et al., 2020 \\
\hline & & PS19 mice & Park et al., 2020 \\
\hline & & Tau.P301L mice & Govaerts et al., 2019 \\
\hline & & pR5 mice & Kindler et al., 2021 \\
\hline & & Tau4R $\Delta \mathrm{K}$ mice & Wei et al., 2021 \\
\hline \multirow[t]{4}{*}{ BOLD } & rs-fMRI & Thy-Tau22 mice & Degiorgis et al., 2020 \\
\hline & & TauRD/ $\Delta$ K280 mice & Green et al., 2019 \\
\hline & & hTau.P301L mice & Detrez et al., 2020 \\
\hline & Task-based fMRI & rTg4510 mice & Nahavandi et al., 2017 \\
\hline Glymphatic system & DCE-MRI & rTg4510 mice & Harrison et al., 2020 \\
\hline \multirow[t]{4}{*}{ Synaptic function } & MEMRI & rTg4510 mice & $\begin{array}{c}\text { Pautler et al., 2003; Perez et al., 2013; Majid et al., 2014; Fontaine et al., 2017; } \\
\text { Bachstetter et al., 2020; Koren et al., } 2020\end{array}$ \\
\hline & & JNPL3 mice & Bertrand et al., 2013 \\
\hline & & Tau-KO mice & Lopes et al., 2016 \\
\hline & & Wtau-Tg mice & Kimura et al., 2007 \\
\hline
\end{tabular}

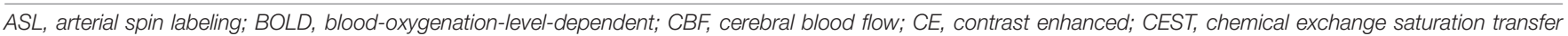

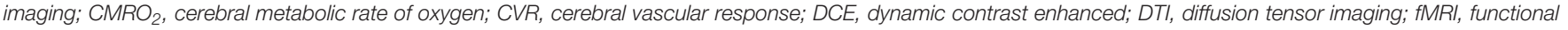

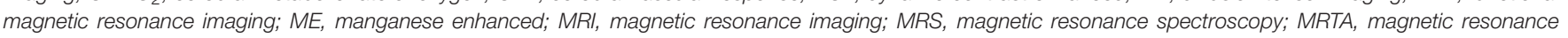

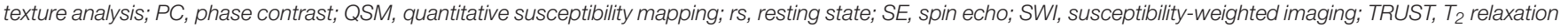
under spin tagging; WM, white matter; w, weighted.

using rs-fMRI (maintained under medetomidine sedation during fMRI), which preceded the occurrence of memory impairment. A different observation was reported by Detrez et al. (2020), who found that progressive tau aggregation did not alter the functional brain network connectivity in hTau.P301L mice at 7 months of age after seeding with K18 tau at 3 months of age (under
$0.5 \%$ isoflurane and medetomidine during $\mathrm{fMRI}$ ) at $7 \mathrm{~T} \mathrm{MRI}$. Using task-based fMRI at 9.4 T, Nahavandi et al. (2017) reported differences in the visual processing pathway and a stronger midbrain BOLD response to visual stimulation in $\mathrm{rTg} 4510$ mice than in wild-type mice at 7.5 months of age. Interpretation of BOLD signals is challenged by their dependence on multiple 
factors, such as baseline physiological state, breathing, animal handling, ventilation, and anesthesia scheme (Grandjean et al., 2014a; Paasonen et al., 2018). In addition, variation in the fMRI signal might partly stem from technical factors, fluctuations, spatial localization, non-linearities, task, pulse sequence used, and data analysis approaches.

\section{Manganese-Enhanced MRI}

Manganese-enhanced MRI (MEMRI) is a sensitive in vivo neuroimaging method that detects the neuronal activity-based transport of $\mathrm{Mn}^{2+}$ into active neurons (Silva and Bock, 2008). Several in vivo MEMRI studies have demonstrated axonal transport deficits in rTg4510 (Perez et al., 2013; Majid et al., 2014; Fontaine et al., 2017; Bachstetter et al., 2020; Koren et al., 2020), Tau-KO (Lopes et al., 2016), JNPL3 (Bertrand et al., 2013), and Wtau-Tg mice (Kimura et al., 2007) compared with control mice (Table 1). Using MEMRI at $7 \mathrm{~T}$, Fontaine et al. (2017) showed elevated changes in tissue $\mathrm{R} 1$ relaxation rates $(\Delta R 1)$ after the administration of $\mathrm{Mn}^{2+}$, indicating early neuronal dysfunction at 3 months of age in rTg4510 mice before the onset of cognitive deficits (Figures 1D-H). However, concerns regarding the neurotoxicity of $\mathrm{Mn}^{2+}$ hinder the wide application of this method.

\section{Arterial Spin Labeling}

Arterial spin labeling MRI has been widely used in the clinical setting as well as in preclinical imaging in animal models. ASL MRI has demonstrated different spatial distributions of hypoperfusion in patients with FTD compared with AD (Du et al., 2006; Verfaillie et al., 2015; Meeter et al., 2017). ASL uses magnetically labeled blood water and allows the direct quantification of absolute cerebral blood flow (CBF) and cerebrovascular reactivity of the whole brain regions. In regions with very short or very long arterial transit times, the accuracy of ASL measurement is compromised. Previous studies on ASL measures of CBF in tauopathy animal models have yielded inconsistent results (Table 1). Park et al. (2020) showed that at 2-3 months of age, rTg4510 mice had comparable resting $\mathrm{CBF}$, attenuated $\mathrm{CBF}$ response to whisker stimulation, and no cortical thinning compared with wild-type mice. Reduced resting $\mathrm{CBF}$ and $\mathrm{CBF}$ responses to whisker stimulation in the neocortex and the hippocampus, along with reduced cortical thickness, were detected at 7-8 months of age compared with wild-type mice (Figures 2A-D; Park et al., 2020). In the PS19 mice, an early impaired resting $\mathrm{CBF}$ and $\mathrm{CBF}$ response to whisker stimulation at 2-3 months of age was detected in the absence of cortical thinning compared with wild-type mice (Figures 2A-D). Moreover, tau induces postsynaptic protein PSD95-neuronal nitric oxide uncoupling and neurovascular dysfunction in rTg4510 and PS19 mice in a neurodegenerationindependent manner (Park et al., 2020). In contrast, a study by Wells et al. (2015b) and Holmes et al. (2016) reported elevated levels of $\mathrm{CBF}$ in the cortex, hippocampus, and thalamus in 7.59.5-month-old rTg4510 mice compared with wild-type mice. Another recent study by Govaerts et al. (2019) showed that the regional CBF levels are comparable between Tau.P301L mice and wild-type mice at 3, 6, and 12 months of age. Kindler et al. (2021) showed a comparable cortical and hippocampal CBF between pR5 mice and wild-type mice at 10 and 18 months of age. Wei et al. (2021) reported a reduced cerebral metabolic rate of oxygen while preserving CBF in Tau $4 \mathrm{R} \Delta \mathrm{K}$ (Tau) mice at 12 months of age compared with wild-type mice by using $\mathrm{T}_{2}$ relaxation under spin tagging, phase contrast, and ASL MRI. For cerebral vascular response quantification, pulsed ASL and pseudocontinuous ASL methods have been utilized. Using a hypercapnia (5\% carbon dioxide)-challenged pulsed ASL vasoreactivity paradigm, Wells et al. (2015a) showed increased vascular responses to hypercapnia conditions in rTg4510 mice compared with wild-type mice at approximately 8 months of age. It is noted that information regarding the amount of carbon dioxide in exhaled air was not provided in this article. The varying results regarding the influence of tau on CBF (increasing, preserved, or reducing) require further investigation.

\section{STRUCTURAL MRI}

\section{Volumetric MRI}

MRI investigations have revealed disease-specific patterns of gray and white matter atrophy in patients with PSP, CBD, Pick's disease, and variants of FTD and $\mathrm{AD}$, providing valuable tools for differential diagnosis (Boxer et al., 2006; Jabbari et al., 2020; Ulugut Erkoyun et al., 2020; Vogel et al., 2021; Young et al., 2021). In animal models of tauopathy, histological studies have demonstrated the deposition of neurofibrillary tangle pathology, particularly in the cortex and hippocampus, accompanied by regional atrophy. Both in vivo and ex vivo MRI studies have been performed to assess structural alterations. Ma et al. (2019) compared the results from in vivo and ex vivo volumetric MRI in rTg4510 mice and reported comparable readouts of brain atrophy compared with wild-type mice. MRI studies in animal models of tauopathies have revealed distinctive neuroimaging features and patterns of brain regional atrophy in $\mathrm{rTg} 4510$, hTau, EC-Tau, rTg21221, and PS19 mice as well as in R962-hTau rats (Table 1). Gray matter atrophy, cortical thinning, hippocampal atrophy, and ventricle enlargement that result from neurodegeneration have been reported in several MR studies in the rTg4510 tau mouse model compared with wild-type mice (Yang et al., 2011; Wells et al., 2015b; Holmes et al., 2016, 2017; Ishikawa et al., 2018; Ni et al., 2018; Ma et al., 2019; Barron et al., 2020; Park et al., 2020). In addition, Colgan et al. (2017) and O'Callaghan et al. (2017) reported tau-related tissue textural alterations using $\mathrm{T}_{2}{ }^{*}$ weighted $\mathrm{MR}$ textural analysis and $\mathrm{T}_{2}{ }^{*}$-weighted quantitative susceptibility mapping (QSM) in rTg4510 mice. In addition to the aforementioned MRI studies, optic nerve thinning and degeneration in the neurosensory retina have been reported in rTg4510 mice (Harrison et al., 2019).

In comparison with wild-type mice, hTau mice showed predominantly cortical thinning and rather spared hippocampi (Andorfer et al., 2003; Hashimoto et al., 2019). For P301S (PS19) mice, Yoshiyama et al. (2007) showed atrophy in the hippocampus and entorhinal cortex at 9-12 months of age and that atrophy was further present in the amygdala and neocortex at later stages (Wu et al., 2019; Takeuchi et al., 2020; Lee et al., 2021). 

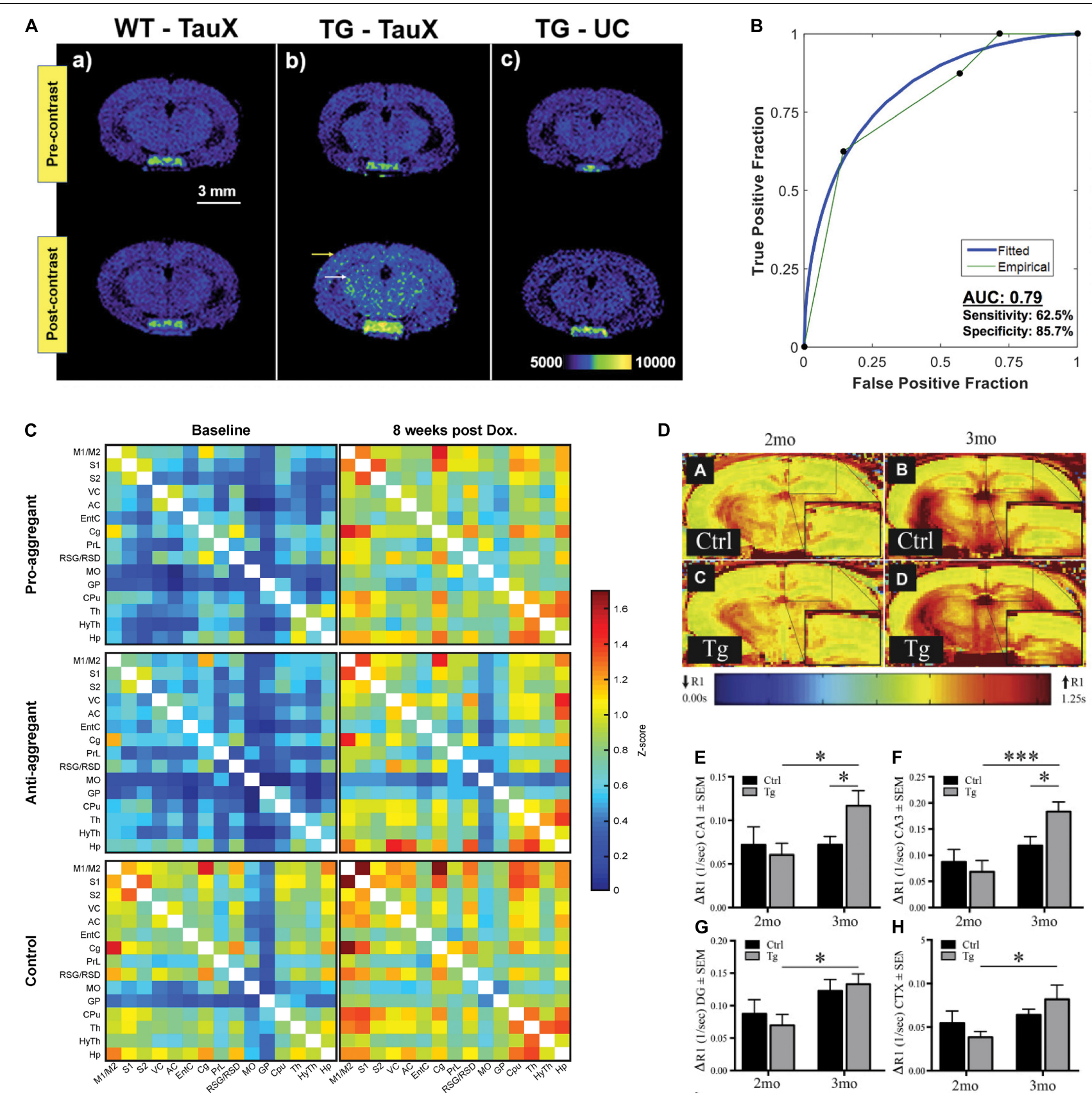

FIGURE 1 | Tau accumulation and functional imaging in tauopathy mouse models. (A,B) Tau imaging. (A) $T_{1}$-weighted spin-echo images demonstrate signal enhancement in delayed post-contrast scans of transgenic P301S mice treated with TauX but not in age-matched controls. Wild-type animals showed no signal enhancement 4 days after the administration of TauX. Transgenic animals show high enhancement in the cortical (yellow arrow) and hippocampal regions (white arrow) 4 days after the administration of TauX. Transgenic animals showed no signal enhancement 4 days after the injection of untargeted contrast. Scale bar represents $3 \mathrm{~mm}$. All animals are shown on the same color bar scale. (B) Receiver operating characteristic curve demonstrating TauX accuracy in identifying early age transgenic animals. Area under the curve is calculated using the empirical curve. Sensitivity describes the true positive rate for transgenic mice given TauX, while specificity is the true negative rate for wild-type mice given TauX and transgenic mice receiving untargeted gadolinium nanoparticle contrast. Reproduced from Badachhape et al. (2020) with permission from Elsevier. (C) Functional connectivity matrices of transgenic rTg4510 and wild-type mice at baseline and after 8weeks of treatment with doxycycline. The pro- and anti-aggregant mice clearly show matrices of lower z score values at baseline (left column). Upon 8weeks of doxycycline treatment (right column), the $z$ score values of the transgenic animals closely approximate those of the control group. Reproduced from Green et al. (2019) with permission from Springer Nature. (D-H) MEMRI-R1 detects early signs of neuronal dysfunction in transgenic rTg4510 mice before the onset of cognitive deficits. (D, A-D) Representative R1 map of (A) 2-month littermate control, (B) 3-month littermate control, (C) 2-month rTg4510 mouse (Tg), and (D) 3-month rTg4510 mouse (Tg). Quantification of $\triangle \mathrm{R} 1$ values in (E) CA1, (F) CA3, (G) dentate gyrus, and (H) superior medial cortex. All values are mean \pm SEM, $n=$ at least 4. $* * * p<0.001, * p<0.05$. Reproduced from Fontaine et al. (2017) with permission from Elsevier. CA1, cornu ammonis 1; CA3, cornu ammonis 3; CTX, cortex; DG, dentate gyrus; MEMRI, manganese-enhanced magnetic resonance imaging. 


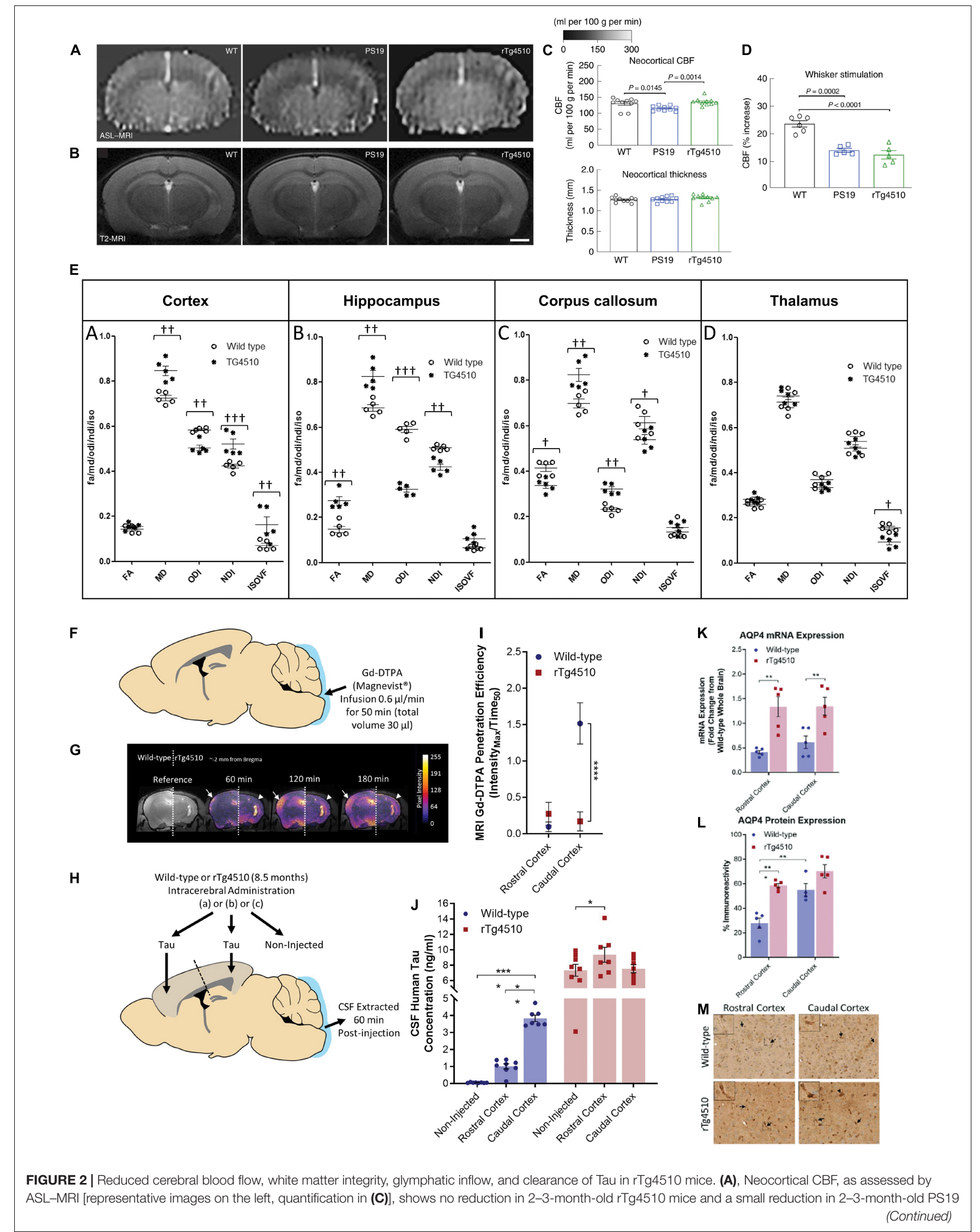


FIGURE 2 | mice compared with age-matched WT mice. N = 10 mice per group; one-way ANOVA with Tukey's test for multiple comparisons. (B) Neocortical thickness, as assessed bilaterally in $\mathrm{T}_{2}$-weighted MRI [images (representative images on the left, quantification in (C)] at the level of the somatosensory cortex (-1.22-1.70mm from bregma), is comparable in PS19, rTg4510, and WT mice. Scale bar, $1 \mathrm{~mm}$. $N=10$ mice per group. (D) The increases in CBF induced in the whisker barrel cortex by mechanical stimulation of facial whiskers ( $N=5$ mice per group; one-way ANOVA with Tukey's test) were markedly attenuated in both PS19 and rTg4510 mice compared with WT mice. Reproduced from Park et al. (2020) with permission from Springer Nature. (E) Neurite orientation dispersion and density imaging for white matter integrity assessment. Region-of-interest quantification of fractional anisotropy, mean diffusivity $\left(\times 10^{-9} \mathrm{~m}^{2} / \mathrm{s}\right)$, orientation dispersion index, neurite density index, and isotropic volume fraction for each animal based on distinct anatomical regions. (A) Cortex, (B) hippocampus, (C) corpus callosum, and (D) thalamus ( $\dagger=p<0.05, \dagger \dagger=p<0.01, \dagger \dagger \dagger=p<0.001$ ). Reproduced from Colgan et al. (2016) with permission from Elsevier. (F) Schematic illustrating infusion of Gd-DTPA into the cisterna magna of the mouse for quantification of glymphatic inflow in the brain. (G) Representative pseudocolor scaled coronal (approximately $-2 \mathrm{~mm}$ from bregma) images of the (left) wild-type and (right) rTg4510 mouse brain, highlighting the difference in the extent of contrast agent infiltration into the caudal cortex [designated by white arrows (wild-type) and arrowheads (rTg4510)] over time. This difference is further exemplified through the calculated Gd-DTPA penetration efficiency data shown in (I). (H) Schematic illustrating brain homogenate injection experiments in which tau-containing brain homogenate was injected into either the rostral or caudal cortex of wild-type and rTg4510 mice, and CSF was extracted from the cisterna magna 60 min later. (J) Tau concentration of CSF samples extracted from experiments shown schematically in d demonstrating reduced clearance from the caudal cortex of rTg4510 mice compared with wild-type animals. Raw data and mean \pm SEM between animals shown in d, and best-fit value and associated $95 \% \mathrm{Cl}$ of sigmoidal fitting of data shown in c. $n=5-8$ per group. Statistical significance is denoted by asterisks: ${ }^{\star \star} p<0.01,{ }^{\star \star \star *} p<0.0001$. AQP4 expression and polarization in rTg4510 mice. Quantification of (K) mRNA and (L) protein expression of AQP4 in the rostral and caudal cortex of wild-type and rTg4510 mice, demonstrating upregulation in rTg4510 mice compared with wild-type controls. (M) Representative example images of brain tissue from wild-type and rTg4510 mice immunohistochemically stained for AQP4. Arrows indicate examples of immune-positive blood vessels in each image, which are shown at greater magnification in insets. Reproduced from Harrison et al. (2020) with permission from the Oxford press. AQP4, aquaporin 4; CSF, cerebrospinal fluid; FA, fractional anisotropy; Gd-DTPA, gadolinium diethylenetriaminepentaacetic acid; IsoVF, isotropic volume fraction; MD; mean diffusivity, NDI, neurite density index; NODDI, neurite orientation dispersion and density imaging; ODI, orientation dispersion index; WT, wild-type.

Takeuchi et al. (2020) demonstrated that tauopathy and MRIassessed brain atrophy and cognitive impairment in PS19 mice can be reversed by nasal vaccine delivery. In EC-TAU mice, Fung et al. (2020) showed that regional hippocampal atrophy (based on tensor-based morphometry analysis) compared with age-matched wild-type mice was associated with tau pathology preceding overt cell death. In rTg21221 mice that overproduced non-aggregating wild-type human tau but lacked neurofibrillary tangle accumulation, mainly ventricle enlargement was observed compared with wild-type mice (Wegmann et al., 2015; Musi et al., 2018). Malcolm et al. (2019) characterized recently developed R962-hTau rats and reported ventricular dilation and hippocampal atrophy in this model.

\section{Diffusion Imaging}

Diffusion imaging is based on the tissue water diffusion rate: DTI enables indirect measurement of the degree of anisotropy and structural orientation (Le Bihan et al., 2001), while diffusion kurtosis imaging (DKI) reports non-Gaussian water diffusion (Jensen and Helpern, 2010). DTI has been widely used to assess white matter integrity alterations non-invasively both in animal models and in the clinical setting (Mori and Zhang, 2006). The DTI scalars reflect various alterations: fractional anisotropy (FA) infers microstructural integrity, axonal diameter, and density of crossing fibers; radial diffusivity (RD) is the diffusivity perpendicular to axonal fibers and reflects myelin abnormalities; mean diffusivity (MD) is the average mobility of water molecules related to the white matter tissue microstructure; and axial diffusivity (AD) is the magnitude of diffusion parallel to fiber tracts associated with axonal pathologies (Assaf and Pasternak, 2008). Several DTI studies in tauopathy models have been reported, including rTg4510 (Sahara et al., 2014; Wells et al., 2015b; Holmes et al., 2016), Thy-Tau22 (Degiorgis et al., 2020), pR5 (Soni et al., 2021), Tg601 (Hara et al., 2017), JNPL3 (Nishioka et al., 2019), and TauRD/ $\Delta$ K280 mice (Green et al.,
2019), with varying results. Sahara et al. (2014) reported an agedependent decrease in FA in the corpus callosum and anterior commissure in rTg4510 mice at 8 months of age, increased RD, and unaltered $\mathrm{MD}$ and $\mathrm{AD}$ in the corpus callosum. Colgan et al. (2016) found a lower FA and a higher MD in the corpus callosum of rTg4510 mice of 8.5 months of age compared with wild-type mice. Using neurite orientation dispersion and density imaging (NODDI) model, Colgan et al. (2016) showed that neurite density index (NDI) was increased in the cortex (with high tau load) but decreased in the hippocampus and corpus callosum of rTg4510 mice compared with wild-type mice, isotropic volume fraction (IsoVF) was increased in the cortex but decreased in the thalamus (a region void of tau) of rTg4510 mice compared with wildtype mice, and orientation dispersion index (ODI) was found to be reduced in the cortex and hippocampus but increased in the corpus callosum of rTg4510 mice compared with wild-type mice (Figure 2E). FA was increased in the hippocampus but reduced in the corpus callosum of $\mathrm{rTg} 4510$ mice compared with wild-type mice (Figure 2E; Colgan et al., 2016). Furthermore, the NDI readout correlated with the level of tau (PG-5 antibody staining) in the gray matter of the rTg4510 mouse brain. Wells et al. (2015b) demonstrated unaltered FA, MD, and AD and an increased RD in the corpus callosum and increased FA and $\mathrm{MD}$ in the gray matter (cortex and hippocampus) in rTg4510 mice compared with wild-type mice. Massalimova et al. (2021) showed decreased FA and increased $\mathrm{MD}, \mathrm{RD}$, and $\mathrm{AD}$ in the corpus callosum and decreased FA in the gray matter of the hippocampus in the pR5 line at 8.5 months of age compared with wild-type mice. Degiorgis et al. (2020) demonstrated a significant decrease in FA and fiber density in Thy-Tau22 mice at 5 months of age compared with wild-type mice. A DTI study in patients with FTD reported reduced FA values in the anterior corpus callosum, anterior and descending cingulum, and uncinate fiber tracts (Zhang et al., 2009; Torso et al., 2021). In comparison, in patients with $\mathrm{AD}$, reduced $\mathrm{FA}$ was reported in the descending cingulum, posterior and anterior cingulum, and uncinate fiber 
tracts, correlating with the increased tau distribution assessed by PET (Kantarci et al., 2017; Jacobs et al., 2018; Sintini et al., 2019; Carlson et al., 2021). Thus, DTI may facilitate the differential diagnosis of FTD and AD in the clinical setting (Torso et al., 2021).

\section{MRI FOR NEUROCHEMICAL PROFILES}

\section{MR Spectroscopy}

Magnetic resonance spectroscopy (MRS) is a highly sensitive MR method for characterizing neurochemical alterations in vivo using the infusion of substrates labeled with magnetic isotopes (Zhu and Barker, 2011). However, MRS has not been translated to clinical usage, where fast, simple, and reliable measurement is essential. A few MRS studies have been reported thus far on tauopathy animal models. Yang et al. (2011) revealed an increase in the hippocampal myoinositol to total creatine ratios $(\mathrm{mIns} / \mathrm{tCr}$, representing gliosis) in rTg4510 mice at 5 and 8 months of age compared with wild-type mice using ${ }^{1} \mathrm{H}$ MRS at $9.4 \mathrm{~T}$. Kim et al. (2017) demonstrated more pronounced neurochemical alterations in the olfactory bulbs than in the hippocampus in rTg4510 mice by using ${ }^{1} \mathrm{H}$ MRS. Nilsen et al. (2013) showed that glutamate metabolism is impaired in $\mathrm{P} 301 \mathrm{~L}$ (pR5) mice compared with wild-type mice by using ${ }^{1} \mathrm{H}$ and ${ }^{13} \mathrm{C}$ MRS.

\section{Chemical Exchange Saturation Transfer MRI}

Molecular MRI based on chemical exchange saturation transfer (CEST) is a highly sensitive method that has enabled the detection of changes in the uptake of glucose, glutamate, and creatine without additional hardware (Nilsen et al., 2013; Mamoune et al., 2021). Recent advances in CEST MRI provide information on oxygen metabolism and tissue metabolite levels in the brain, with an increased translational value compared with $\mathrm{MRS}(\mathrm{Oz}$ et al., 2014). Clinical CEST MRI has been reported using 3 and 7 T MRI (Jones et al., 2018; van Zijl and Knutsson, 2019; van Zijl et al., 2021). Protein-based amide proton transfer-weighted
(APTw) CEST MRI has been reported in patients with mild cognitive impairment (Heo et al., 2019; Zhou et al., 2019; Zhang et al., 2020). Glucose CEST has been applied in several tau animal models (Table 1). Lauretti et al. (2017) showed reductions in brain glucose uptake and synaptic function, increased tau accumulation and phosphorylation, and memory impairments in hTau mice compared with control mice. Similar observations of reduced glucose uptake were reported in $\mathrm{rTg} 4510$ mice compared with wild-type mice (Wells et al., 2015b; Holmes et al., 2016). Chen et al. (2020) demonstrated reduced glucose uptake in a Tau4R $\Delta \mathrm{K}$ (Tau) mouse model by using on-resonance variable delay multiple pulse (onVDMP) MRI with improved labeling efficiency and sensitivity (Xu et al., 2019). Crescenzi et al. (2014, 2017) demonstrated that there is a reduction in glutamate levels in the hippocampus of PS19 mice compared with wild-type mice, as measured by longitudinal glutamate CEST. Glutamate reduction was found to be associated with the level of synapse loss Crescenzi et al., 2014, 2017). Using creatine CEST, Chen et al. (2021) recently detected a reduction in the cerebral creatine level in Tau4R $\Delta \mathrm{K}$ (Tau) mice compared with wild-type mice.

\section{DISCUSSION}

There has been a rapid development in MRI technology in recent years, particularly in high-field MR scanners. For clinical application in humans, 7 and 10.5T MRIs have been reported (Ehman et al., 2017; Ladd et al., 2018). For small animal imaging, 7, 9.4, 11.7, 16, and up to $21.1 \mathrm{~T}$ high-field MRI has been utilized in the laboratory (Schepkin et al., 2010; Miyaoka and Lehnert, 2020; Ni, 2021), providing insights into the function and pathophysiology of the brain. Higher magnetic fields substantially increase the sensitivity and signalto-noise ratio for MRI, although the tissue heating and nonuniformity of the radio-frequency field might affect the image quality. In addition, hybrid imaging systems such as PET-MRI have been increasingly used in preclinical imaging research for complementary molecular and anatomical information (Musafargani et al., 2018; Stortz et al., 2018).

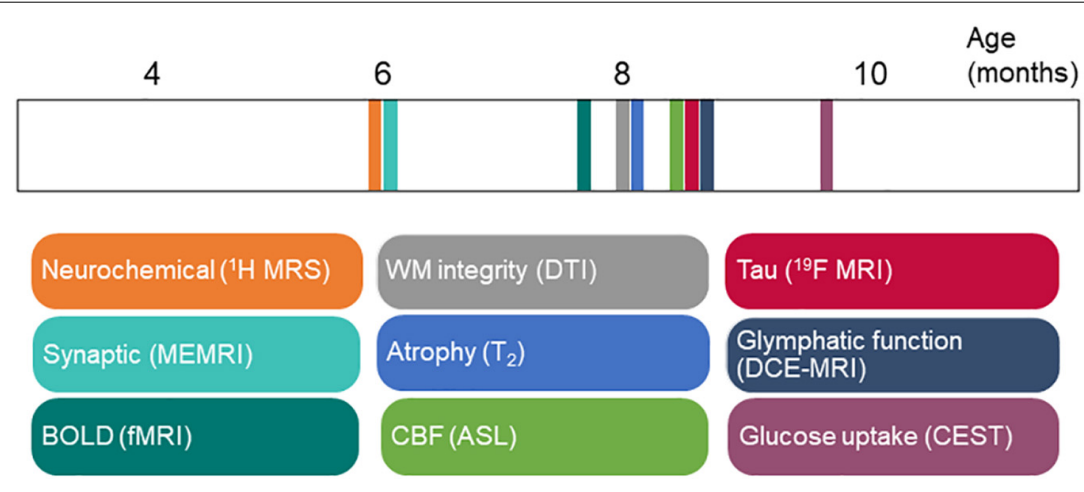

FIGURE 3 | Time course of magnetic resonance imaging (MRI) biomarker changes in rTg4510 mice in Table 1. ASL, arterial spin labeling; BOLD, blood-oxygenation-level-dependent; CBF, cerebral blood flow; CEST, chemical exchange saturation transfer imaging; DCE, dynamic contrast enhanced; DTI, diffusion tensor imaging; fMRI, functional magnetic resonance imaging; ME, manganese enhanced; MRI: magnetic resonance imaging; MRS, magnetic resonance spectroscopy; WM, white matter. 


\section{Difference Among Animal Models}

Different tauopathy mouse/rat models show distinct tempospatial patterns of pathological features, including tau deposits and regional atrophy (Jankowsky and Zheng, 2017; Götz et al., 2018). Tau accumulates in the entorhinal cortex, forebrain, and hippocampus of rTg4510 mice and mainly in the brainstem and spinal cord of the PS19 model (Clavaguera et al., 2009; Maruyama et al., 2013; Wegmann et al., 2019). In rTg4510 mice, atrophy was observed both in the cortex and in the hippocampus, while in hTau mice, cortical thinning was observed while the hippocampus was spared (Andorfer et al., 2003; Santacruz et al., 2005; Ni et al., 2018). Systematic approaches are needed for the direct comparison of datasets from different model systems (Oblak et al., 2020; Sukoff Rizzo et al., 2020).

\section{Methodology and Reproducibility Considerations}

Diverging results have been reported in the aforementioned functional MRI studies in tauopathy mice. The various anesthetic regimens used in these studies add to the complexity in interpreting the results. Anesthesia usage brings the benefit of excellent motion control while at the cost of potential interference with measures, particularly in fMRI-related experiments. The regional connectivity in the mouse brain has been shown to be influenced by the different anesthesia protocols utilized (Wu et al., 2017; van Alst et al., 2019). In addition to the isoflurane or low-dose isoflurane + medetomidine sedation that has been used in the aforementioned studies, ketamine and xylazine mixtures have also been reportedly used to achieve stable states in mice or rats (Grandjean et al., 2014b, 2020; Shim et al., 2018; Mandino et al., 2020). A recent systematic review summarized the influence of anesthetics, doses, and timing on fMRI results in rodents (Steiner et al., 2021). Thus, standardization of pipelines is important for better interpretation of the results from fMRI studies. Physiological parameters such as heartbeat, breathing rate, and mouse/rat body temperature are routinely included in all in vivo animal studies. In addition, three physiological parameters, namely, blood oxygenation (arterial blood pressure of oxygen), ventilation (arterial partial pressure of carbon dioxide), and arterial blood pressure, can influence BOLD fMRI readouts in various study designs (Steiner et al., 2020) and are thus recommended for inclusion in the monitoring of animal status. Moreover, Chen et al. (2019) reported real-time monitoring and adaptive modulation of the brain hemodynamic system to further facilitate fMRI experiments.

\section{Time Course of MRI Biomarkers in rTg4510 Mice}

The $\mathrm{rTg} 4510$ mouse model is one of the most widely used tauopathy animal models (Santacruz et al., 2005). rTg4510 mice express high levels of mutant tau (approximately 13 times compared with the levels of endogenous murine tau) and develop neurofibrillary tangles (from 4 months of age), neuroinflammation, neuronal loss, and behavioral impairments with increasing age (Ramsden et al., 2005). A recent study showed that factors other than hTau overexpression contributed to the tauopathy-like phenotype in this model (Gamache et al., 2019). Although no MR angiography has been performed in $\mathrm{rTg} 4510$ mice, Harrison et al. (2020) investigated the paravascular fluid (glymphatic) movement in this model: impaired glymphatic flow and clearance of tau in rTg4510 mice compared with wildtype mice were detected by using dynamic contrast-enhanced MRI assisted with Gd-DTPA (Figures 2F-M). In this study, we summarized the findings from the aforementioned MRI studies regarding the time course of events in rTg4510 mice (Figure 3). Following known tau accumulation from 2 months of age (Santacruz et al., 2005), early alterations in synaptic function and neurochemical profiles were observed. The changes in BOLD fMRI, CBF, white matter integrity, and regional atrophy appeared at a later stage. Most of the reported MRI studies are crosssectional in rTg4510 mice of different age groups. More MRI studies with longitudinal and multiparameter designs are needed to elucidate the time course of these events.

\section{Translational Value}

Longitudinal multimodal MRI, such as ASL, DTI, and rs-fMRI, has shown great potential as a diagnostic biomarker in FTD (Jiskoot et al., 2019) and for monitoring clinical trials (Staffaroni et al., 2019), providing added value to patients. Preclinical studies in animal models recapitulating human tauopathy provide an opportunity to study disease mechanisms and for extrapolation to human studies. In animal models, the measurements of structural alterations such as brain regional atrophy and white matter integrity yielded more homogenous results compared with the functional changes. As discussed in the "Functional Imaging" section, functional imaging studies using rs-fMRI and ASL MRI for CBF measurement have resulted in different observations in tau animal models. With the presence of such a discrepancy, special attention and further improvement of the protocol and standardization will be required if functional connectivity and $\mathrm{CBF}$ are to be used as evaluation readouts for treatment studies in animal models. Several recent studies have utilized awake fMRI to investigate the dysfunction of neural circuits in rodent disease models (Stenroos et al., 2018; Bergmann et al., 2020; Tsurugizawa et al., 2020; Dinh et al., 2021). Such a method will greatly increase the translational potential of the results from rodents to humans.

In summary, MRI studies in tauopathy animal models have improved our understanding of the roles of tau and the progression of pathophysiology and facilitated the evaluation of treatment studies targeting tau. Further MRI studies are needed to further characterize the functional, structural, and molecular alterations in various tauopathy animal models.

\section{AUTHOR CONTRIBUTIONS}

The author confirms being the sole contributor of this work and has approved it for publication.

\section{FUNDING}

RN received funding from Helmut Horten Stiftung and Vontobel Stiftung, University of Zurich (reference no. MEDEF-20-021). 


\section{REFERENCES}

Albert, M., Mairet-Coello, G., Danis, C., Lieger, S., Caillierez, R., Carrier, S., et al. (2019). Prevention of tau seeding and propagation by immunotherapy with a central tau epitope antibody. Brain 142, 1736-1750. doi: 10.1093/brain/awz100

Andorfer, C., Kress, Y., Espinoza, M., de Silva, R., Tucker, K. L., Barde, Y. A., et al. (2003). Hyperphosphorylation and aggregation of tau in mice expressing normal human tau isoforms. J. Neurochem. 86, 582-590. doi: 10.1046/j.14714159.2003.01879.x

Assaf, Y., and Pasternak, O. (2008). Diffusion tensor imaging (DTI)-based white matter mapping in brain research: a review. J. Mol. Neurosci. 34, 51-61. doi: 10.1007/s12031-007-0029-0

Ayalon, G., Lee, S. H., Adolfsson, O., Foo-Atkins, C., Atwal, J. K., Blendstrup, M., et al. (2021). Antibody semorinemab reduces tau pathology in a transgenic mouse model and engages tau in patients with Alzheimer's disease. Sci. Transl. Med 13:eabb2639. doi: 10.1126/scitranslmed.abb2639

Bachstetter, A. D., Morganti, J. M., Bodnar, C. N., Webster, S. J., Higgins, E. K., Roberts, K. N., et al. (2020). The effects of mild closed head injuries on tauopathy and cognitive deficits in rodents: primary results in wild type and rTg4510 mice, and a systematic review. Exp. Neurol. 326:113180. doi: 10.1016/ j.expneurol.2020.113180

Badachhape, A., Parekh, P. A., Mu, Q., Bhavane, R., Srivastava, M., Stupin, I., et al. (2020). A novel MRI contrast agent for identifying hyperphosphorylative neurons as a marker of future tau pathology. Alzheimers Dement. 16:e041080.

Ballatore, C., Lee, V. M., and Trojanowski, J. Q. (2007). Tau-mediated neurodegeneration in Alzheimer's disease and related disorders. Nat. Rev. Neurosci. 8, 663-672. doi: 10.1038/nrn2194

Barron, A. M., Ji, B., Fujinaga, M., Zhang, M. R., Suhara, T., Sahara, N., et al. (2020). In vivo positron emission tomography imaging of mitochondrial abnormalities in a mouse model of tauopathy. Neurobiol. Aging 94, 140-148. doi: 10.1016/j. neurobiolaging.2020.05.003

Bergmann, E., Gofman, X., Kavushansky, A., and Kahn, I. (2020). Individual variability in functional connectivity architecture of the mouse brain. Commun. Biol. 3:738. doi: 10.1038/s42003-020-01472-5

Bertrand, A., Khan, U., Hoang, D. M., Novikov, D. S., Krishnamurthy, P., Rajamohamed Sait, H. B., et al. (2013). Non-invasive, in vivo monitoring of neuronal transport impairment in a mouse model of tauopathy using MEMRI. Neuroimage 64, 693-702. doi: 10.1016/j.neuroimage.2012.08.065

Boxer, A. L., Geschwind, M. D., Belfor, N., Gorno-Tempini, M. L., Schauer, G. F., Miller, B. L., et al. (2006). Patterns of brain atrophy that differentiate corticobasal degeneration syndrome from progressive supranuclear palsy. Arch. Neurol. 63, 81-86. doi: 10.1001/archneur.63.1.81

Boxer, A. L., Gold, M., Feldman, H., Boeve, B. F., Dickinson, S. L., Fillit, H., et al. (2020). New directions in clinical trials for frontotemporal lobar degeneration: methods and outcome measures. Alzheimers Dement. 16, 131-143. doi: 10.1016/ j.jalz.2019.06.4956

Boxer, A. L., Qureshi, I., Ahlijanian, M., Grundman, M., Golbe, L. I., Litvan, I., et al. (2019). Safety of the tau-directed monoclonal antibody BIIB092 in progressive supranuclear palsy: a randomised, placebo-controlled, multiple ascending dose phase 1b trial. Lancet Neurol. 18, 549-558. doi: 10.1016/S1474-4422(19)30 139-5

Brendel, M., Jaworska, A., Probst, F., Overhoff, F., Korzhova, V., Lindner, S., et al. (2016). Small-animal PET imaging of tau pathology with 18F-THK5117 in 2 transgenic mouse models. J. Nucl. Med. 57, 792-798. doi: 10.2967/jnumed.115. 163493

Buckner, R. L., and DiNicola, L. M. (2019). The brain's default network: updated anatomy, physiology and evolving insights. Nat. Rev. Neurosci. 20, 593-608. doi: 10.1038/s41583-019-0212-7

Busche, M. A., Eichhoff, G., Adelsberger, H., Abramowski, D., Wiederhold, K. H., Haass, C., et al. (2008). Clusters of hyperactive neurons near amyloid plaques in a mouse model of Alzheimer's disease. Science 321, 1686-1689. doi: 10.1126/ science. 1162844

Calvo-Rodriguez, M., Hou, S. S., Snyder, A. C., Dujardin, S., Shirani, H., Nilsson, K. P. R., et al. (2019). In vivo detection of tau fibrils and amyloid $\beta$ aggregates with luminescent conjugated oligothiophenes and multiphoton microscopy. Acta Neuropathol. Commun. 7:171. doi: 10.1186/s40478-019-0832-1

Carlson, M. L., Toueg, T. N., Khalighi, M. M., Castillo, J., Shen, B., Azevedo, E. C., et al. (2021). Hippocampal subfield imaging and fractional anisotropy show parallel changes in Alzheimer's disease tau progression using simultaneous tau-PET/MRI at 3T. Alzheimers Dement. 13:e12218. doi: 10.1002/dad2.12218

Cao, L., Kong, Y., Ji, B., Ren, Y., Guan, Y., and Ni, R. (2022). Positron emission tomography in animal models of tauopathies. Front. Aging Neurosci. 13:913. doi: 10.3389/fnagi.2021.761913

Chakraborty, P., Rivière, G., Liu, S., de Opakua, A. I., Dervişoğlu, R., Hebestreit, A., et al. (2021). Co-factor-free aggregation of tau into seeding-competent RNAsequestering amyloid fibrils. Nat. Commun. 12:4231. doi: 10.1038/s41467-02124362-8

Chaney, A. M., Lopez-Picon, F. R., Serrière, S., Wang, R., Bochicchio, D., Webb, S. D., et al. (2021). Prodromal neuroinflammatory, cholinergic and metabolite dysfunction detected by PET and MRS in the TgF344-AD transgenic rat model of AD: a collaborative multi-modal study. Theranostics 11, 6644-6667. doi: 10.7150/thno. 56059

Chen, L., van Zijl, P. C. M., Wei, Z., Lu, H., Duan, W., Wong, P. C., et al. (2021). Early detection of Alzheimer's disease using creatine chemical exchange saturation transfer magnetic resonance imaging. Neuroimage 236:118071. doi: 10.1016/j.neuroimage.2021.118071

Chen, L., Wei, Z., Chan, K. W. Y., Li, Y., Suchal, K., Bi, S., et al. (2020). D-Glucose uptake and clearance in the tauopathy Alzheimer's disease mouse brain detected by on-resonance variable delay multiple pulse MRI. J. Cereb. Blood Flow Metab. 41, 1013-1025. doi: 10.1177/0271678X20941264

Chen, X., Sobczak, F., Chen, Y., Jiang, Y., Qian, C., Lu, Z., et al. (2019). Mapping optogenetically-driven single-vessel fMRI with concurrent neuronal calcium recordings in the rat hippocampus. Nat. Commun. 10:5239. doi: 10.1038/ s41467-019-12850-x

Clavaguera, F., Bolmont, T., Crowther, R. A., Abramowski, D., Frank, S., Probst, A., et al. (2009). Transmission and spreading of tauopathy in transgenic mouse brain. Nat. Cell Biol. 11, 909-913. doi: 10.1038/ncb1901

Colgan, N., Ganeshan, B., Harrison, I. F., Ismail, O., Holmes, H. E., Wells, J. A., et al. (2017). In vivo imaging of tau pathology using magnetic resonance imaging textural analysis. Front. Neurosci. 11:599. doi: 10.3389/fnins.2017.00599

Colgan, N., Siow, B., O'Callaghan, J. M., Harrison, I. F., Wells, J. A., Holmes, H. E., et al. (2016). Application of neurite orientation dispersion and density imaging (NODDI) to a tau pathology model of Alzheimer's disease. Neuroimage 125, 739-744. doi: 10.1016/j.neuroimage.2015.10.043

Congdon, E. E., and Sigurdsson, E. M. (2018). Tau-targeting therapies for Alzheimer disease. Nat. Rev. Neurol. 14, 399-415. doi: 10.1038/s41582-0180013-z

Crescenzi, R., DeBrosse, C., Nanga, R. P., Byrne, M. D., Krishnamoorthy, G., D'Aquilla, K., et al. (2017). Longitudinal imaging reveals subhippocampal dynamics in glutamate levels associated with histopathologic events in a mouse model of tauopathy and healthy mice. Hippocampus 27, 285-302. doi: 10.1002/ hipo. 22693

Crescenzi, R., DeBrosse, C., Nanga, R. P., Reddy, S., Haris, M., Hariharan, H., et al. (2014). In vivo measurement of glutamate loss is associated with synapse loss in a mouse model of tauopathy. Neuroimage 101, 185-192. doi: 10.1016/j. neuroimage.2014.06.067

de Calignon, A., Polydoro, M., Suárez-Calvet, M., William, C., Adamowicz, D. H., Kopeikina, K. J., et al. (2012). Propagation of tau pathology in a model of early Alzheimer's disease. Neuron 73, 685-697. doi: 10.1016/j.neuron.2011. 11.033

Degiorgis, L., Karatas, M., Sourty, M., Faivre, E., Lamy, J., Noblet, V., et al. (2020). Brain network remodelling reflects tau-related pathology prior to memory deficits in Thy-Tau22 mice. Brain 143, 3748-3762. doi: 10.1093/brain/awaa312

Detrez, J. R., Ben-Nejma, I. R. H., Van Kolen, K., Van Dam, D., De Deyn, P. P., Fransen, E., et al. (2020). Progressive tau aggregation does not alter functional brain network connectivity in seeded hTau.P301L mice. Neurobiol. Dis. 143:105011. doi: 10.1016/j.nbd.2020.105011

DeVos, S. L., Miller, R. L., Schoch, K. M., Holmes, B. B., Kebodeaux, C. S., Wegener, A. J., et al. (2017). Tau reduction prevents neuronal loss and reverses pathological tau deposition and seeding in mice with tauopathy. Sci. Transl. Med. 9:eaag0481. doi: 10.1126/scitranslmed.aag0481

Dinh, T. N. A., Jung, W. B., Shim, H.-J., and Kim, S.-G. (2021). Characteristics of fMRI responses to visual stimulation in anesthetized vs. awake mice. NeuroImage 226:117542. doi: 10.1016/j.neuroimage.2020.117542

Du, A. T., Jahng, G. H., Hayasaka, S., Kramer, J. H., Rosen, H. J., Gorno-Tempini, M. L., et al. (2006). Hypoperfusion in frontotemporal dementia and Alzheimer 
disease by arterial spin labeling MRI. Neurology 67, 1215-1220. doi: 10.1212/01. wnl.0000238163.71349.78

Ehman, E. C., Johnson, G. B., Villanueva-Meyer, J. E., Cha, S., Leynes, A. P., Larson, P. E. Z., et al. (2017). PET/MRI: where might it replace PET/CT? J. Magn. Reson. Imaging 46, 1247-1262. doi: 10.1002/jmri.2 5711

Filipcik, P., Zilka, N., Bugos, O., Kucerak, J., Koson, P., Novak, P., et al. (2012). First transgenic rat model developing progressive cortical neurofibrillary tangles. Neurobiol. Aging 33, 1448-1456. doi: 10.1016/j.neurobiolaging.2010.10.015

Fontaine, S. N., Ingram, A., Cloyd, R. A., Meier, S. E., Miller, E., Lyons, D., et al. (2017). Identification of changes in neuronal function as a consequence of aging and tauopathic neurodegeneration using a novel and sensitive magnetic resonance imaging approach. Neurobiol. Aging 56, 78-86. doi: 10.1016/j. neurobiolaging.2017.04.007

Franzmeier, N., Dewenter, A., Frontzkowski, L., Dichgans, M., Rubinski, A., Neitzel, J., et al. (2020). Patient-centered connectivity-based prediction of tau pathology spread in Alzheimer's disease. Sci. Adv. 6:eabd1327. doi: 10.1126/ sciadv.abd 1327

Fu, H., Possenti, A., Freer, R., Nakano, Y., Hernandez Villegas, N. C., Tang, M., et al. (2019). A tau homeostasis signature is linked with the cellular and regional vulnerability of excitatory neurons to tau pathology. Nat. Neurosci. 22, 47-56. doi: 10.1038/s41593-018-0298-7

Fung, C. W., Guo, J., Fu, H., Figueroa, H. Y., Konofagou, E. E., and Duff, K. E. (2020). Atrophy associated with tau pathology precedes overt cell death in a mouse model of progressive tauopathy. Sci. Adv. 6:eabc8098. doi: 10.1126/ sciadv.abc8098

Gamache, J., Benzow, K., Forster, C., Kemper, L., Hlynialuk, C., Furrow, E., et al. (2019). Factors other than hTau overexpression that contribute to tauopathylike phenotype in rTg4510 mice. Nat. Commun. 10:2479. doi: 10.1038/s41467019-10428-1

Goedert, M., Jakes, R., Spillantini, M. G., Hasegawa, M., Smith, M. J., and Crowther, R. A. (1996). Assembly of microtubule-associated protein tau into Alzheimerlike filaments induced by sulphated glycosaminoglycans. Nature 383, 550-553. doi: $10.1038 / 383550 \mathrm{a} 0$

Gomez-Murcia, V., Sandau, U., Ferry, B., Parrot, S., Laurent, C., Basquin, M., et al. (2020). Hyperexcitability and seizures in the THY-Tau 22 mouse model of tauopathy. Neurobiol. Aging 94, 265-270. doi: 10.1016/j.neurobiolaging.2020. 06.004

Götz, J., Bodea, L.-G., and Goedert, M. (2018). Rodent models for Alzheimer disease. Nat. Rev. Neurosci. 19, 583-598. doi: 10.1038/s41583-018-0054-8

Govaerts, K., Lechat, B., Struys, T., Kremer, A., Borghgraef, P., Van Leuven, F., et al. (2019). Longitudinal assessment of cerebral perfusion and vascular response to hypoventilation in a bigenic mouse model of Alzheimer's disease with amyloid and tau pathology. NMR Biomed. 32:e4037. doi: 10.1002/nbm. 4037

Grandjean, J., Canella, C., Anckaerts, C., Ayranc1, G., Bougacha, S., Bienert, T., et al. (2020). Common functional networks in the mouse brain revealed by multi-centre resting-state fMRI analysis. Neuroimage 205:116278. doi: 10.1016/ j.neuroimage.2019.116278

Grandjean, J., Schroeter, A., Batata, I., and Rudin, M. (2014a). Optimization of anesthesia protocol for resting-state fMRI in mice based on differential effects of anesthetics on functional connectivity patterns. Neuroimage 102(Pt 2), 838-847. doi: 10.1016/j.neuroimage.2014.08.043

Grandjean, J., Schroeter, A., He, P., Tanadini, M., Keist, R., Krstic, D., et al. (2014b). Early alterations in functional connectivity and white matter structure in a transgenic mouse model of cerebral amyloidosis. J. Neurosci. 34, 13780-13789. doi: 10.1523/JNEUROSCI.4762-13.2014

Green, C., Sydow, A., Vogel, S., Anglada-Huguet, M., Wiedermann, D., Mandelkow, E., et al. (2019). Functional networks are impaired by elevated tauprotein but reversible in a regulatable Alzheimer's disease mouse model. Mol. Neurodegener. 14:13. doi: 10.1186/s13024-019-0316-6

Grossman, M. (2021). Lessons learned from a progressive supranuclear palsy trial. Lancet Neurol. 20, 162-163. doi: 10.1016/S1474-4422(21)00035-1

Hara, Y., Motoi, Y., Hikishima, K., Mizuma, H., Onoe, H., Matsumoto, S. E., et al. (2017). Involvement of the septo-hippocampal cholinergic pathway in association with septal acetylcholinesterase upregulation in a mouse model of tauopathy. Curr. Alzheimer Res. 14, 94-103. doi: 10.2174/ 1567205013666160602235800
Harrison, I. F., Ismail, O., Machhada, A., Colgan, N., Ohene, Y., Nahavandi, P., et al. (2020). Impaired glymphatic function and clearance of tau in an Alzheimer's disease model. Brain 143, 2576-2593. doi: 10.1093/brain/awaa179

Harrison, I. F., Whitaker, R., Bertelli, P. M., O'Callaghan, J. M., Csincsik, L., Bocchetta, M., et al. (2019). Optic nerve thinning and neurosensory retinal degeneration in the rTg4510 mouse model of frontotemporal dementia. Acta Neuropathol. Commun. 7:4.

Hashimoto, S., Matsuba, Y., Kamano, N., Mihira, N., Sahara, N., Takano, J., et al. (2019). Tau binding protein CAPON induces tau aggregation and neurodegeneration. Nat. Commun. 10:2394.

Heo, H.-Y., Han, Z., Jiang, S., Schär, M., van Zijl, P. C. M., and Zhou, J. (2019). Quantifying amide proton exchange rate and concentration in chemical exchange saturation transfer imaging of the human brain. NeuroImage 189, 202-213. doi: 10.1016/j.neuroimage.2019.01.034

Holmes, H. E., Colgan, N., Ismail, O., Ma, D., Powell, N. M., O’Callaghan, J. M., et al. (2016). Imaging the accumulation and suppression of tau pathology using multiparametric MRI. Neurobiol. Aging 39, 184-194. doi: 10.1016/j. neurobiolaging.2015.12.001

Holmes, H. E., Powell, N. M., Ma, D., Ismail, O., Harrison, I. F., Wells, J. A., et al. (2017). Comparison of in vivo and ex vivo MRI for the detection of structural abnormalities in a mouse model of tauopathy. Front. Neuroinform. 11:20. doi: 10.3389/fninf.2017.00020

Hoover, B. R., Reed, M. N., Su, J., Penrod, R. D., Kotilinek, L. A., Grant, M. K., et al. (2010). Tau mislocalization to dendritic spines mediates synaptic dysfunction independently of neurodegeneration. Neuron 68, 1067-1081. doi: 10.1016/j. neuron.2010.11.030

Hosokawa, M., Masuda-Suzukake, M., Shitara, H., Shimozawa, A., Suzuki, G., Kondo, H., et al. (2021). Development of a novel tau propagation mouse model endogenously expressing 3 and 4 repeat tau isoforms. Brain Online ahead of print doi: 10.1093/brain/awab289

Ishikawa, A., Tokunaga, M., Maeda, J., Minamihisamatsu, T., Shimojo, M., Takuwa, H., et al. (2018). In vivo visualization of tau accumulation, microglial activation, and brain atrophy in a mouse model of tauopathy rTg4510. J. Alzheimers Dis. 61, 1037-1052. doi: 10.3233/JAD- 170509

Ising, C., Venegas, C., Zhang, S., Scheiblich, H., Schmidt, S. V., Vieira-Saecker, A., et al. (2019). NLRP3 inflammasome activation drives tau pathology. Nature 575, 669-673. doi: 10.1038/s41586-019-1769-z

Jabbari, E., Holland, N., Chelban, V., Jones, P. S., Lamb, R., Rawlinson, C., et al. (2020). Diagnosis across the spectrum of progressive supranuclear palsy and corticobasal syndrome. JAMA Neurol. 77, 377-387. doi: 10.1001/jamaneurol. 2019.4347

Jacobs, H. I. L., Hedden, T., Schultz, A. P., Sepulcre, J., Perea, R. D., Amariglio, R. E., et al. (2018). Structural tract alterations predict downstream tau accumulation in amyloid-positive older individuals. Nat. Neurosci. 21, 424-431. doi: 10.1038/ s41593-018-0070-z

Jankowsky, J. L., and Zheng, H. (2017). Practical considerations for choosing a mouse model of Alzheimer's disease. Mol. Neurodegener. 12:89. doi: 10.1186/ s13024-017-0231-7

Jensen, J. H., and Helpern, J. A. (2010). MRI quantification of non-gaussian water diffusion by kurtosis analysis. NMR Biomed. 23, 698-710. doi: 10.1002/nbm. 1518

Jiskoot, L. C., Panman, J. L., Meeter, L. H., Dopper, E. G. P., Donker Kaat, L., Franzen, S., et al. (2019). Longitudinal multimodal MRI as prognostic and diagnostic biomarker in presymptomatic familial frontotemporal dementia. Brain 142, 193-208. doi: 10.1093/brain/awy288

Jones, K. M., Pollard, A. C., and Pagel, M. D. (2018). Clinical applications of chemical exchange saturation transfer (CEST) MRI. J. Magn. Reson. Imaging 47, 11-27. doi: 10.1002/jmri.25838

Kantarci, K., Murray, M. E., Schwarz, C. G., Reid, R. I., Przybelski, S. A., Lesnick, T., et al. (2017). White-matter integrity on DTI and the pathologic staging of Alzheimer's disease. Neurobiol Aging 56, 172-179. doi: 10.1016/j. neurobiolaging.2017.04.024

Kim, E. J., Hwang, J. L., Gaus, S. E., Nana, A. L., Deng, J., Brown, J. A., et al. (2020). Evidence of corticofugal tau spreading in patients with frontotemporal dementia. Acta Neuropathol. 139, 27-43. doi: 10.1007/s00401-01902075-z

Kim, J., Choi, I. Y., Duff, K. E., and Lee, P. (2017). Progressive pathological changes in neurochemical profile of the hippocampus and early changes in the olfactory 
bulbs of tau transgenic mice (rTg4510). Neurochem. Res. 42, 1649-1660. doi: 10.1007/s11064-017-2298-5

Kimura, T., Yamashita, S., Fukuda, T., Park, J.-M., Murayama, M., Mizoroki, T., et al. (2007). Hyperphosphorylated tau in parahippocampal cortex impairs place learning in aged mice expressing wild-type human tau. EMBO J. 26, 5143-5152. doi: 10.1038/sj.emboj.7601917

Kindler, D., Maschio, C., Ni, R., Zerbi, V., Razansky, D., and Klohs, J. (2021). Arterial spin labeling demonstrates preserved regional cerebral blood flow in the P301L mouse model of tauopathy. J. Cereb. Blood Flow Metab. Online ahead of print doi: 10.1177/0271678X211062274

Koren, S. A., Hamm, M. J., Cloyd, R., Fontaine, S. N., Chishti, E., Lanzillotta, C., et al. (2020). Novel therapeutic targets to mitigate early neuronal dysfunction and cognitive deficits in tauopathy. bioRxiv [Priprint] doi: 10.1101/2020.07.31. 229583

Ladd, M. E., Bachert, P., Meyerspeer, M., Moser, E., Nagel, A. M., Norris, D. G., et al. (2018). Pros and cons of ultra-high-field MRI/MRS for human application. Prog. Nucl. Magn. Reson. Spectrosc. 109, 1-50. doi: 10.1016/j.pnmrs.2018.06.001

Lasagna-Reeves, C. A., Castillo-Carranza, D. L., Sengupta, U., Clos, A. L., Jackson, G. R., and Kayed, R. (2011). Tau oligomers impair memory and induce synaptic and mitochondrial dysfunction in wild-type mice. Mol. Neurodegener. 6:39. doi: 10.1186/1750-1326-6-39

Lauretti, E., Li, J. G., Di Meco, A., and Praticò, D. (2017). Glucose deficit triggers tau pathology and synaptic dysfunction in a tauopathy mouse model. Transl. Psychiatry 7:e1020. doi: 10.1038/tp.2016.296

Le Bihan, D., Mangin, J. F., Poupon, C., Clark, C. A., Pappata, S., Molko, N., et al. (2001). Diffusion tensor imaging: concepts and applications. J. Magn. Reson. Imaging 13, 534-546. doi: 10.1002/jmri.1076

Lee, S. E., Khazenzon, A. M., Trujillo, A. J., Guo, C. C., Yokoyama, J. S., Sha, S. J., et al. (2014). Altered network connectivity in frontotemporal dementia with C9orf72 hexanucleotide repeat expansion. Brain 137, 3047-3060. doi: 10.1093/ brain/awu248

Lee, S. H., Meilandt, W. J., Xie, L., Gandham, V. D., Ngu, H., Barck, K. H., et al. (2021). Trem2 restrains the enhancement of tau accumulation and neurodegeneration by $\beta$-amyloid pathology. Neuron 109, 1283.e12861301.e1286. doi: 10.1016/j.neuron.2021.02.010

Lee, V. M., Goedert, M., and Trojanowski, J. Q. (2001). Neurodegenerative tauopathies. Annu. Rev. Neurosci. 24, 1121-1159.

Lewis, J., McGowan, E., Rockwood, J., Melrose, H., Nacharaju, P., Van Slegtenhorst, M., et al. (2000). Neurofibrillary tangles, amyotrophy and progressive motor disturbance in mice expressing mutant (P301L) tau protein. Nat. Genet. 25, 402-405.

Lopes, S., Vaz-Silva, J., Pinto, V., Dalla, C., Kokras, N., Bedenk, B., et al. (2016). Tau protein is essential for stress-induced brain pathology. Proc. Natl. Acad. Sci. U.S.A. 113:E3755. doi: 10.1073/pnas.1600953113

Ma, D., Holmes, H. E., Cardoso, M. J., Modat, M., Harrison, I. F., Powell, N. M., et al. (2019). Study the longitudinal in vivo and cross-sectional ex vivo brain volume difference for disease progression and treatment effect on mouse model of tauopathy using automated mri structural parcellation. Front. Neurosci. 13:11. doi: 10.3389/fnins.2019.00011

Majid, T., Ali, Y. O., Venkitaramani, D. V., Jang, M.-K., Lu, H.-C., and Pautler, R. G. (2014). In vivo axonal transport deficits in a mouse model of fronto-temporal dementia. NeuroImage 4, 711-717. doi: 10.1016/j.nicl.2014. 02.005

Malcolm, J. C., Breuillaud, L., Do Carmo, S., Hall, H., Welikovitch, L. A., Macdonald, J. A., et al. (2019). Neuropathological changes and cognitive deficits in rats transgenic for human mutant tau recapitulate human tauopathy. Neurobiol. Dis. 127, 323-338. doi: 10.1016/j.nbd.2019.03.018

Mamoune, K. E., Barantin, L., Adriaensen, H., and Tillet, Y. (2021). Application of chemical exchange saturation transfer (CEST) in neuroimaging. J. Chem. Neuroanat. 114:101944. doi: 10.1016/j.jchemneu.2021.101944

Mandino, F., Cerri, D. H., Garin, C. M., Straathof, M., van Tilborg, G. A. F., Chakravarty, M. M., et al. (2020). Animal functional magnetic resonance imaging: trends and path toward standardization. Front. Neuroinform. 13:78. doi: $10.3389 /$ fninf.2019.00078

Maruyama, M., Shimada, H., Suhara, T., Shinotoh, H., Ji, B., Maeda, J., et al. (2013). Imaging of tau pathology in a tauopathy mouse model and in Alzheimer patients compared to normal controls. Neuron 79, 1094-1108. doi: 10.1016/j. neuron.2013.07.037
Massalimova, A., Ni, R., Nitsch, R. M., Reisert, M., von Elverfeldt, D., and Klohs, J. (2021). Diffusion tensor imaging reveals whole-brain microstructural changes in the P301L mouse model of tauopathy. Neurodegener. Dis. 20, 173-184. doi: $10.1159 / 000515754$

Meeter, L. H., Kaat, L. D., Rohrer, J. D., and van Swieten, J. C. (2017). Imaging and fluid biomarkers in frontotemporal dementia. Nat. Rev. Neurol. 13, 406-419. doi: $10.1038 /$ nrneurol.2017.75

Miyaoka, R. S., and Lehnert, A. (2020). Small animal PET: a review of what we have done and where we are going. Phys. Med. Biol. Online ahead of print doi: 10.1088/1361-6560/ab8f71

Mori, S., and Zhang, J. (2006). Principles of diffusion tensor imaging and its applications to basic neuroscience research. Neuron 51, 527-539. doi: 10.1016/ j.neuron.2006.08.012

Mullard, A. (2021). Failure of first anti-tau antibody in Alzheimer disease highlights risks of history repeating. Nat. Rev. Drug. Discov. England 20, 3-5. doi: 10.1038/ d41573-020-00217-7

Musafargani, S., Ghosh, K. K., Mishra, S., Mahalakshmi, P., Padmanabhan, P., and Gulyás, B. (2018). PET/MRI: a frontier in era of complementary hybrid imaging. Eur. J. Hybrid Imaging 2:12. doi: 10.1186/s41824-018-0030-6

Musi, N., Valentine, J. M., Sickora, K. R., Baeuerle, E., Thompson, C. S., Shen, Q., et al. (2018). Tau protein aggregation is associated with cellular senescence in the brain. Aging Cell 17:e12840. doi: 10.1111/acel.12840

Nahavandi, P., Niranjan, A., Ohene, Y., Harrison, I. F., Ismail, O., Murray, T. K., et al. (2017). [IC-P-193]: FMRI of visual stimuli in a tau model of alzheimer's disease. Alzheimers Dement. 13:142.

Ni, R. (2021). Magnetic resonance imaging in animal models of Alzheimer's disease amyloidosis. Int. J. Mol. Sci. 22:12768. doi: 10.3390/ijms2223 12768

Ni, R., Chen, Z., Gerez, J. A., Shi, G., Zhou, Q., Riek, R., et al. (2020a). Detection of cerebral tauopathy in P301L mice using high-resolution large-field multifocal illumination fluorescence microscopy. Biomed. Opt. Express 11, 4989-5002. doi: 10.1364/BOE.395803

Ni, R., Zarb, Y., Kuhn, G. A., Müller, R., Yundung, Y., Nitsch, R. M., et al. (2020b). SWI and phase imaging reveal intracranial calcifications in the P301L mouse model of human tauopathy. MAGMA 33, 769-781. doi: 10.1007/s10334-02000855-3

Ni, R., Ji, B., Ono, M., Sahara, N., Zhang, M. R., Aoki, I., et al. (2018). Comparative in-vitro and in-vivo quantifications of pathological tau deposits and their association with neurodegeneration in tauopathy mouse models. J. Nucl. Med. 59, 960-966. doi: 10.2967/jnumed.117.201632

Nilsen, L. H., Rae, C., Ittner, L. M., Götz, J., and Sonnewald, U. (2013). Glutamate metabolism is impaired in transgenic mice with tau hyperphosphorylation. J. Cereb. Blood Flow Metab. 33, 684-691. doi: 10.1038/jcbfm. 2012.212

Nishioka, C., Liang, H.-F., Barsamian, B., and Sun, S.-W. (2019). Amyloidbeta induced retrograde axonal degeneration in a mouse tauopathy model. NeuroImage 189, 180-191. doi: 10.1016/j.neuroimage.2019.01.007

Novak, P., Kovacech, B., Katina, S., Schmidt, R., Scheltens, P., Kontsekova, E., et al. (2021). ADAMANT: a placebo-controlled randomized phase 2 study of AADvac1, an active immunotherapy against pathological tau in Alzheimer's disease. Nat. Aging 1, 521-534. doi: 10.1038/s43587-021-00070-2

Oblak, A. L., Forner, S., Territo, P. R., Sasner, M., Carter, G. W., Howell, G. R., et al. (2020). Model organism development and evaluation for late-onset Alzheimer's disease: MODEL-AD. Alzheimers Dement. 6:e12110.

O'Callaghan, J., Holmes, H., Powell, N., Wells, J. A., Ismail, O., Harrison, I. F., et al. (2017). Tissue magnetic susceptibility mapping as a marker of tau pathology in Alzheimer's disease. Neuroimage 159, 334-345. doi: 10.1016/j.neuroimage.2017. 08.003

Ono, M., Sahara, N., Kumata, K., Ji, B., Ni, R., Koga, S., et al. (2017). Distinct binding of PET ligands PBB3 and AV-1451 to tau fibril strains in neurodegenerative tauopathies. Brain 140, 764-780. doi: 10.1093/brain/ aww339

Oz, G., Alger, J. R., Barker, P. B., Bartha, R., Bizzi, A., Boesch, C., et al. (2014). Clinical proton MR spectroscopy in central nervous system disorders. Radiology 270, 658-679. doi: 10.1148/radiol.13130531

Paasonen, J., Stenroos, P., Salo, R. A., Kiviniemi, V., and Gröhn, O. (2018). Functional connectivity under six anesthesia protocols and the awake condition in rat brain. Neuroimage 172, 9-20. doi: 10.1016/j.neuroimage.2018.01.014 
Parekh, P., Badachhape, A., Mu, Q., Bhavane, R., Srivastava, M., Devkota, L., et al. (2021). Early detection of tau pathology. bioRxiv [Preprint] doi: 10.1101/2021. 05.14 .444233

Park, L., Hochrainer, K., Hattori, Y., Ahn, S. J., Anfray, A., Wang, G., et al. (2020). Tau induces PSD95-neuronal NOS uncoupling and neurovascular dysfunction independent of neurodegeneration. Nat. Neurosci. 23, 1079-1089. doi: 10.1038/ s41593-020-0686-7

Pautler, R. G., Mongeau, R., and Jacobs, R. E. (2003). In vivo trans-synaptic tract tracing from the murine striatum and amygdala utilizing manganese enhanced MRI (MEMRI). Magn. Reson. Med. 50, 33-39. doi: 10.1002/mrm.1 0498

Perez, P. D., Hall, G., Kimura, T., Ren, Y., Bailey, R. M., Lewis, J., et al. (2013). In vivo functional brain mapping in a conditional mouse model of human tauopathy (taup3011) reveals reduced neural activity in memory formation structures. Mol. Neurodegener. 8:9. doi: 10.1186/1750-1326-8-9

Przybyla, M., van Eersel, J., van Hummel, A., van der Hoven, J., Sabale, M., Harasta, A., et al. (2020). Onset of hippocampal network aberration and memory deficits in P301S tau mice are associated with an early gene signature. Brain 143, 1889-1904. doi: 10.1093/brain/awaa133

Ramsden, M., Kotilinek, L., Forster, C., Paulson, J., McGowan, E., SantaCruz, K., et al. (2005). Age-dependent neurofibrillary tangle formation, neuron loss, and memory impairment in a mouse model of human tauopathy (P301L). J. Neurosci. 25, 10637-10647. doi: 10.1523/JNEUROSCI.3279-05.2005

Roberts, M., Sevastou, I., Imaizumi, Y., Mistry, K., Talma, S., Dey, M., et al. (2020). Pre-clinical characterisation of E2814, a high-affinity antibody targeting the microtubule-binding repeat domain of tau for passive immunotherapy in Alzheimer's disease. Acta Neuropathol. Commun. 8:13. doi: 10.1186/s40478020-0884-2

Sahara, N., Perez, P. D., Lin, W.-L., Dickson, D. W., Ren, Y., Zeng, H., et al. (2014). Age-related decline in white matter integrity in a mouse model of tauopathy: an in vivo diffusion tensor magnetic resonance imaging study. Neurobiol. Aging 35, 1364-1374. doi: 10.1016/j.neurobiolaging.2013.12.009

Saito, T., Mihira, N., Matsuba, Y., Sasaguri, H., Hashimoto, S., Narasimhan, S., et al. (2019). Humanization of the entire murine Mapt gene provides a murine model of pathological human tau propagation. J. Biol. Chem. 294, 12754-12765. doi: 10.1074/jbc.RA119.009487

Santacruz, K., Lewis, J., Spires, T., Paulson, J., Kotilinek, L., Ingelsson, M., et al. (2005). Tau suppression in a neurodegenerative mouse model improves memory function. Science 309, 476-481. doi: 10.1126/science.1113694

Schepkin, V. D., Brey, W. W., Gor'kov, P. L., and Grant, S. C. (2010). Initial in vivo rodent sodium and proton MR imaging at 21.1 T. Magn. Reson. Imaging 28, 400-407. doi: 10.1016/j.mri.2009.10.002

Shim, H. J., Jung, W. B., Schlegel, F., Lee, J., Kim, S., and Kim, S. G. (2018). Mouse fMRI under ketamine and xylazine anesthesia: robust contralateral somatosensory cortex activation in response to forepaw stimulation. Neuroimage 177, 30-44. doi: 10.1016/j.neuroimage.2018.04.062

Silva, A. C., and Bock, N. A. (2008). Manganese-enhanced MRI: an exceptional tool in translational neuroimaging. Schizophr. Bull. 34, 595-604. doi: 10.1093/ schbul/sbn056

Sintini, I., Schwarz, C. G., Martin, P. R., Graff-Radford, J., Machulda, M. M., Senjem, M. L., et al. (2019). Regional multimodal relationships between tau, hypometabolism, atrophy, and fractional anisotropy in atypical Alzheimer's disease. Hum. Brain Mapp. 40, 1618-1631. doi: 10.1002/hbm.24473

Soni, N., Medeiros, R., Alateeq, K., To, X. V., and Nasrallah, F. A. (2021). Diffusion tensor imaging detects acute pathology-specific changes in the P301L tauopathy mouse model following traumatic brain injury. Front. Neurosci. 15:106. doi: 10.3389/fnins.2021.611451

Spinelli, E. G., Ghirelli, A., Basaia, S., Cividini, C., Riva, N., Canu, E., et al. (2021). Structural MRI signatures in genetic presentations of the frontotemporal dementia/motor neuron disease spectrum. Neurology 97, e1594-e1607. doi: 10.1212/WNL.0000000000012702

Staffaroni, A. M., Ljubenkov, P. A., Kornak, J., Cobigo, Y., Datta, S., Marx, G., et al. (2019). Longitudinal multimodal imaging and clinical endpoints for frontotemporal dementia clinical trials. Brain 142, 443-459. doi: 10.1093/brain/ awy319

Steiner, A. R., Rousseau-Blass, F., Schroeter, A., Hartnack, S., and BettschartWolfensberger, R. (2020). Systematic review: anaesthetic protocols and management as confounders in rodent blood oxygen level dependent functional magnetic resonance imaging (BOLD fMRI)-part a: effects of changes in physiological parameters. Front. Neurosci. 14:577119. doi: 10.3389/fnins.2020. 577119

Steiner, A. R., Rousseau-Blass, F., Schroeter, A., Hartnack, S., and BettschartWolfensberger, R. (2021). Systematic review: anesthetic protocols and management as confounders in rodent blood oxygen level dependent functional magnetic resonance imaging (BOLD fMRI) - part B: effects of anesthetic agents, doses and timing. Animals 11:199. doi: 10.3390/ani11010199

Stenroos, P., Paasonen, J., Salo, R. A., Jokivarsi, K., Shatillo, A., Tanila, H., et al. (2018). Awake rat brain functional magnetic resonance imaging using standard radio frequency coils and a 3D printed restraint kit. Front. Neurosci. 12:548. doi: 10.3389/fnins.2018.00548

Stortz, G., Thiessen, J. D., Bishop, D., Khan, M. S., Kozlowski, P., Retière, F., et al. (2018). Performance of a PET insert for high-resolution small-animal PET/MRI at 7 tesla. J. Nucl. Med. 59, 536-542. doi: 10.2967/jnumed.116.187666

Sukoff Rizzo, S. J., Masters, A., Onos, K. D., Quinney, S., Sasner, M., Oblak, A., et al. (2020). Improving preclinical to clinical translation in Alzheimer's disease research. Alzheimers Dement. 6:e12038. doi: 10.1002/trc2.12038

Tagai, K., Ono, M., Kubota, M., Kitamura, S., Takahata, K., Seki, C., et al. (2020). High-contrast in vivo imaging of tau pathologies in Alzheimer's and non-Alzheimer's disease tauopathies. Neuron 109, 42.e8-58.e8. doi: 10.1016/j. neuron.2020.09.042

Takeuchi, H., Imamura, K., Ji, B., Tsukita, K., Enami, T., Takao, K., et al. (2020). Nasal vaccine delivery attenuates brain pathology and cognitive impairment in tauopathy model mice. NPJ Vaccines 5:28. doi: 10.1038/s41541-020-0172-y

Torso, M., Ridgway, G. R., Jenkinson, M., Chance, S., and the Frontotemporal Lobar Degeneration Neuroimaging Initiative and the 4-Repeat Tau Neuroimaging Initiative (2021). Intracortical diffusion tensor imaging signature of microstructural changes in frontotemporal lobar degeneration. Alzheimers Res. Ther. 13:180. doi: 10.1186/s13195-021-00914-4

Tsurugizawa, T., Tamada, K., Ono, N., Karakawa, S., Kodama, Y., Debacker, C., et al. (2020). Awake functional MRI detects neural circuit dysfunction in a mouse model of autism. Sci. Adv. 6:eaav4520. doi: 10.1126/sciadv.aav4520

Ulugut Erkoyun, H., Groot, C., Heilbron, R., Nelissen, A., van Rossum, J., Jutten, R., et al. (2020). A clinical-radiological framework of the right temporal variant of frontotemporal dementia. Brain 143, 2831-2843. doi: 10.1093/brain/ awaa225

Vagenknecht, P., Ono, M., Luzgin, A., Ji, B., Higuchi, M., Noain, D., et al. (2021). Non-invasive imaging of tau-targeted probe uptake by whole brain multispectral optoacoustic tomography. bioRxiv [Preprint] doi: 10.1101/2021.07.10. 451626

van Alst, T. M., Wachsmuth, L., Datunashvili, M., Albers, F., Just, N., Budde, T., et al. (2019). Anesthesia differentially modulates neuronal and vascular contributions to the BOLD signal. Neuroimage 195, 89-103. doi: 10.1016/j. neuroimage.2019.03.057

van Zijl, P., and Knutsson, L. (2019). In vivo magnetic resonance imaging and spectroscopy. Technological advances and opportunities for applications continue to abound. J. Magn. Reson. 306, 55-65. doi: 10.1016/j.jmr.2019. 07.034

van Zijl, P. C. M., Brindle, K., Lu, H., Barker, P. B., Edden, R., Yadav, N., et al. (2021). Hyperpolarized MRI, functional MRI, MR spectroscopy and CEST to provide metabolic information in vivo. Curr. Opin. Chem. Biol. 63, 209-218. doi: 10.1016/j.cbpa.2021.06.003

Verfaillie, S. C., Adriaanse, S. M., Binnewijzend, M. A., Benedictus, M. R., Ossenkoppele, R., Wattjes, M. P., et al. (2015). Cerebral perfusion and glucose metabolism in Alzheimer's disease and frontotemporal dementia: two sides of the same coin? Eur. Radiol. 25, 3050-3059. doi: 10.1007/s00330-015-3696-1

Villemagne, V. L., Fodero-Tavoletti, M. T., Masters, C. L., and Rowe, C. C. (2015). Tau imaging: early progress and future directions. Lancet Neurol. 14, 114-124. doi: 10.1016/S1474-4422(14)70252-2

Vogel, J. W., Young, A. L., Oxtoby, N. P., Smith, R., Ossenkoppele, R., Strandberg, O. T., et al. (2021). Four distinct trajectories of tau deposition identified in Alzheimer's disease. Nat. Med. 27, 871-881. doi: 10.1038/s41591-021-01309-6

Wahsner, J., Gale, E. M., Rodríguez-Rodríguez, A., and Caravan, P. (2019). Chemistry of MRI contrast agents: current challenges and new frontiers. Chem. Rev. 119, 957-1057. doi: 10.1021/acs.chemrev.8b00363

Wang, X., Li, W., Marcus, J., Pearson, M., Song, L., Smith, K., et al. (2020). MK8719 , a novel and selective O-GlcNAcase inhibitor that reduces the formation 
of pathological tau and ameliorates neurodegeneration in a mouse model of tauopathy. J. Pharmacol. Exp. Ther. 374, 252-263. doi: 10.1124/jpet.120.266122

Wegmann, S., Bennett, R. E., Delorme, L., Robbins, A. B., Hu, M., McKenzie, D., et al. (2019). Experimental evidence for the age dependence of tau protein spread in the brain. Sci. Adv. 5:eaaw6404. doi: 10.1126/sciadv.aaw6404

Wegmann, S., Maury, E. A., Kirk, M. J., Saqran, L., Roe, A., DeVos, S. L., et al. (2015). Removing endogenous tau does not prevent tau propagation yet reduces its neurotoxicity. Embo J. 34, 3028-3041. doi: 10.15252/embj.201592748

Wei, Z., Xu, J., Chen, L., Hirschler, L., Barbier, E. L., Li, T., et al. (2021). Brain metabolism in tau and amyloid mouse models of Alzheimer's disease: an MRI study. NMR Biomed. 34:e4568. doi: 10.1002/nbm.4568

Wells, J. A., Holmes, H. E., O’Callaghan, J. M., Colgan, N., Ismail, O., Fisher, E. M., et al. (2015a). Increased cerebral vascular reactivity in the tau expressing rTg4510 mouse: evidence against the role of tau pathology to impair vascular health in Alzheimer's disease. J. Cereb. Blood Flow Metab. 35, 359-362. doi: 10.1038/jcbfm.2014.224

Wells, J. A., O’Callaghan, J. M., Holmes, H. E., Powell, N. M., Johnson, R. A., Siow, B., et al. (2015b). In vivo imaging of tau pathology using multi-parametric quantitative MRI. Neuroimage 111, 369-378. doi: 10.1016/j.neuroimage.2015. 02.023

Wu, J. W., Hussaini, S. A., Bastille, I. M., Rodriguez, G. A., Mrejeru, A., Rilett, K., et al. (2016). Neuronal activity enhances tau propagation and tau pathology in vivo. Nat. Neurosci. 19, 1085-1092. doi: 10.1038/nn.4328

Wu, Q., Lin, Y., Gu, J., and Sigurdsson, E. M. (2018). Dynamic assessment of tau immunotherapies in the brains of live animals by two-photon imaging. EBioMedicine 35, 270-278. doi: 10.1016/j.ebiom.2018.08.041

Wu, T., Dejanovic, B., Gandham, V. D., Gogineni, A., Edmonds, R., Schauer, S., et al. (2019). Complement C3 is activated in human AD Brain and is required for neurodegeneration in mouse models of amyloidosis and tauopathy. Cell Rep. 28, 2111.e2116-2123.e2116. doi: 10.1016/j.celrep.2019.07.060

Wu, T., Grandjean, J., Bosshard, S. C., Rudin, M., Reutens, D., and Jiang, T. (2017). Altered regional connectivity reflecting effects of different anaesthesia protocols in the mouse brain. Neuroimage 149, 190-199. doi: 10.1016/j.neuroimage.2017. 01.074

Xie, Z., Yang, D., Stephenson, D., Morton, D., Hicks, C., Brown, T., et al. (2010). Characterizing the regional structural difference of the brain between tau transgenic (rTg4510) and wild-type mice using MRI. Med. Image Comput. Comput. Assist. Interv. 13, 308-315. doi: 10.1007/978-3-642-15705-9_38

Xu, X., Xu, J., Chan, K. W. Y., Liu, J., Liu, H., Li, Y., et al. (2019). GlucoCEST imaging with on-resonance variable delay multiple pulse (onVDMP) MRI. Magn. Reson. Med. 81, 47-56. doi: 10.1002/mrm.27364

Yanagisawa, D., Ibrahim, N. F., Taguchi, H., Morikawa, S., Kato, T., Hirao, K., et al. (2018). Fluorine-19 magnetic resonance imaging probe for the detection of tau pathology in female rTg4510 mice. J. Neurosci. Res. 96, 841-851. doi: 10.1002/jnr. 24188
Yang, D., Xie, Z., Stephenson, D., Morton, D., Hicks, C. D., Brown, T. M., et al. (2011). Volumetric MRI and MRS provide sensitive measures of Alzheimer's disease neuropathology in inducible Tau transgenic mice (rTg4510). NeuroImage 54, 2652-2658. doi: 10.1016/j.neuroimage.2010.10.067

Yoshiyama, Y., Higuchi, M., Zhang, B., Huang, S. M., Iwata, N., Saido, T. C., et al. (2007). Synapse loss and microglial activation precede tangles in a P301S tauopathy mouse model. Neuron 53, 337-351. doi: 10.1016/j.neuron.2007.01. 010

Young, A. L., Bocchetta, M., Russell, L. L., Convery, R. S., Peakman, G., Todd, E., et al. (2021). Characterizing the clinical features and atrophy patterns of MAPTrelated frontotemporal dementia with disease progression modeling. Neurology 97, e941-e952. doi: 10.1212/WNL.0000000000012410

Zhang, Y., Schuff, N., Du, A. T., Rosen, H. J., Kramer, J. H., Gorno-Tempini, M. L., et al. (2009). White matter damage in frontotemporal dementia and Alzheimer's disease measured by diffusion MRI. Brain 132, 2579-2592. doi: 10.1093/brain/awp071

Zhang, Z., Zhang, C., Yao, J., Chen, X., Gao, F., Jiang, S., et al. (2020). Proteinbased amide proton transfer-weighted MR imaging of amnestic mild cognitive impairment. NeuroImage 25:102153. doi: 10.1016/j.nicl.2019.102153

Zhou, J., Greicius, M. D., Gennatas, E. D., Growdon, M. E., Jang, J. Y., Rabinovici, G. D., et al. (2010). Divergent network connectivity changes in behavioural variant frontotemporal dementia and Alzheimer's disease. Brain 133, 1352 1367. doi: 10.1093/brain/awq075

Zhou, J., Heo, H. Y., Knutsson, L., van Zijl, P. C. M., and Jiang, S. (2019). APTweighted MRI: techniques, current neuro applications, and challenging issues. J. Magn. Reson. Imaging 50, 347-364. doi: 10.1002/jmri.26645

Zhu, H., and Barker, P. B. (2011). MR spectroscopy and spectroscopic imaging of the brain. Methods Mol. Biol. 711, 203-226. doi: 10.1007/978-1-61737-992-5_9

Conflict of Interest: The author declares that the research was conducted in the absence of any commercial or financial relationships that could be construed as a potential conflict of interest.

Publisher's Note: All claims expressed in this article are solely those of the authors and do not necessarily represent those of their affiliated organizations, or those of the publisher, the editors and the reviewers. Any product that may be evaluated in this article, or claim that may be made by its manufacturer, is not guaranteed or endorsed by the publisher.

Copyright (c) $2022 \mathrm{Ni}$. This is an open-access article distributed under the terms of the Creative Commons Attribution License (CC BY). The use, distribution or reproduction in other forums is permitted, provided the original author(s) and the copyright owner(s) are credited and that the original publication in this journal is cited, in accordance with accepted academic practice. No use, distribution or reproduction is permitted which does not comply with these terms. 